\title{
Characterization of Erythromycin Analogs by Collisional Activated Dissociation and Infrared Multiphoton Dissociation in a Quadrupole Ion Trap
}

\author{
Matthew C. Crowe and Jennifer S. Brodbelt \\ Department of Chemistry and Biochemistry, University of Texas at Austin, Austin, Texas, USA
}

\author{
Brian J. Goolsby \\ Motorola DigitalDNA Laboratories, Austin, Texas, USA \\ Paul Hergenrother \\ Department of Chemistry, University of Illinois, Urbana, Illinois, USA
}

The effectiveness of two activation techniques, collision activated dissociation (CAD) and infrared multiphoton dissociation (IRMPD), is compared for structural characterization of protonated and lithium-cationized macrolides and a series of synthetic precursors in a quadrupole ion trap (QIT). Generally, cleavage of the glycosidic linkages attaching the sugars to the macrolide ring and water losses constitute the major fragmentation pathways for most of the protonated compounds. In the IRMPD spectra, a diagnostic fragment ion assigned as the desosamine ion is a dominant ion that is not observed in the CAD spectra because of the higher $\mathrm{m} / \mathrm{z}$ limit of the storage range required during collisional activation. Activation of the lithium-cationized species results in new diagnostic fragmentation pathways that are particularly useful for confirming the identities of the protecting groups in the synthetic precursors. Multi-step IRMPD allows mapping of the fragmentation genealogies in greater detail and supports the proposed structures of the fragment ions. (J Am Soc Mass Spectrom 2002, 13, 630-649) ( 2002 American Society for Mass Spectrometry

I nterest in the analysis of macrolide antibiotics has grown in recent years as new compounds, resulting from the manipulation of the biosynthetic pathways of Streptomyces bacteria, may offer improved activities against antibiotic-resistant bacteria [1]. Novel analogs of macrolide compounds are also produced from modifications of erythromycin during attempts at total synthesis [2]. The clinical testing of these erythromycin analogs for bacteriostatic potential, possible human toxicity, and pharmacokinetics requires effective analytical techniques. Mass spectrometry has been utilized in several recent studies aimed at identifying the structures and fragmentation pathways of macrolide antibiotics [3-9]. For example, Gross and co-workers used fast atom bombardment (FAB) to create both protonated and alkali metal cationized species of erythromycin A, megalomicin A, desmycosin, megalalosamine, and tylo-

Published online April 22, 2002

Address reprint requests to Dr. J. S. Brodbelt, Department of Chemistry and Biochemistry, University of Texas at Austin, Austin, TX 78712-1167, USA. E-mail: jbrodbelt@mail.utexas.edu sin, followed by CAD for structural characterization [3]. They noted that the protonated macrolides gave fragmentation patterns that lacked mid-range fragment ions, whereas the alkali metal cationized species gave a greater variety of fragment ions. Gates et al. used isotopic labeling to determine the origin of the initial water loss from protonated erythromycin [4,5]. For these studies, electrospray ionization (ESI) was used to introduce samples into either a Fourier transform ion cyclotron resonance (FTICR) mass spectrometer (for accurate mass measurements), a quadrupole-time-offlight (Q-TOF) instrument, or a quadrupole ion trap for MS/MS experiments. Based on the ${ }^{18} \mathrm{O}-$-labeling, it was found that the first loss of water occured from the C-9 carbonyl group, indicating that the carbonyl oxygen was protonated, not the more basic amine group in the desosamine moiety. They also confirmed via $\mathrm{MS}^{n}$ experiments that the first macrolide ring cleavage involved the $\mathrm{C}-13$ position and adjacent oxygen, with the net loss identified as a substituted ketone moiety [4]. Volmer and Hui incubated erythromycin in aqueous solutions at non-physiological $\mathrm{pH}$ [6], and subsequently 


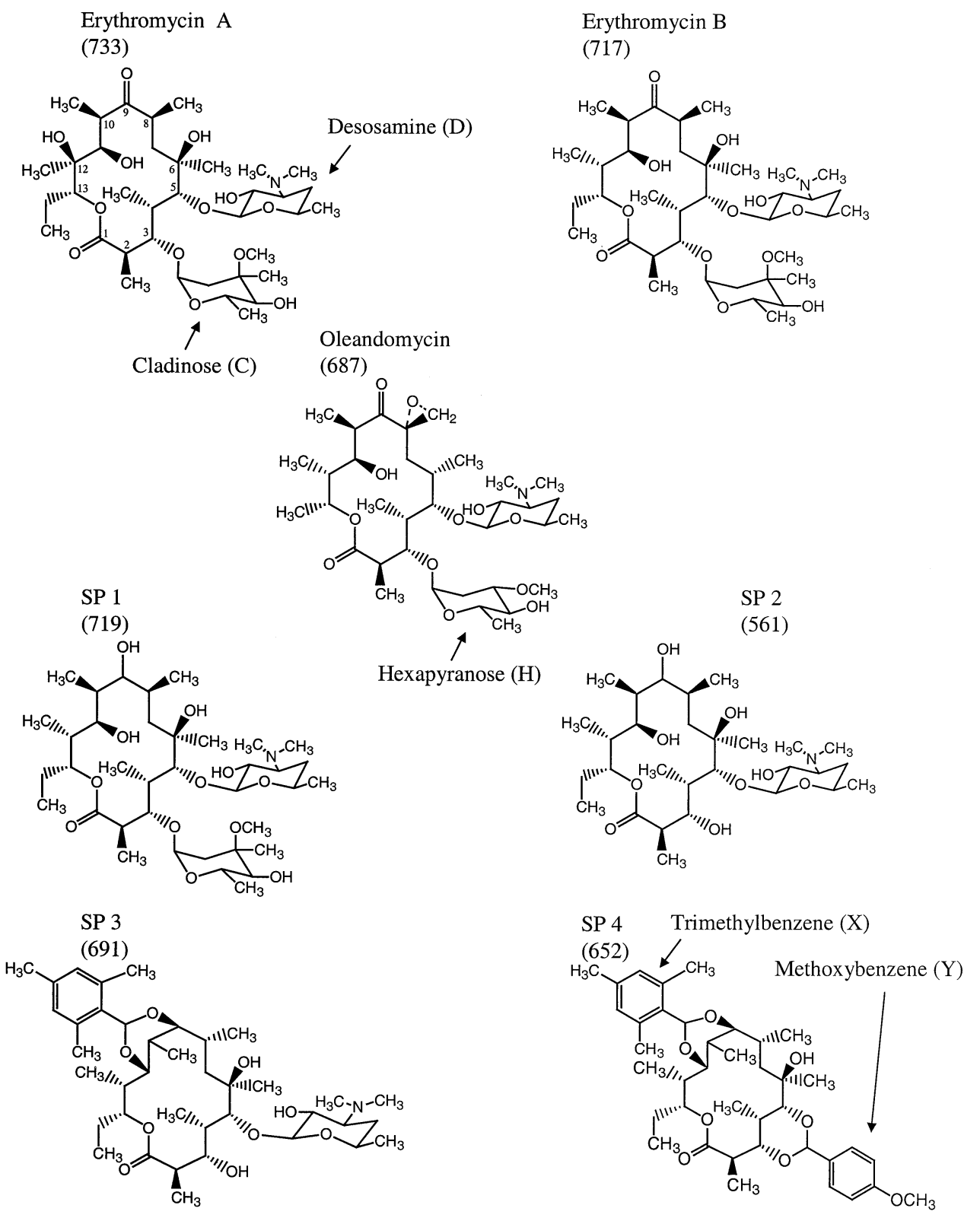

Figure 1. Structures of macrolides (molecular weight in Da).

used solid phase microextraction/high performance liquid chromatography/ESI-MS to determine the decomposition products of protonated erythromycin in a triple quadrupole mass spectrometer. Ling et al. demonstrated the use of matrix assisted laser desorption ionization (MALDI) TOF-MS to quantify numerous classes of antibiotics, including macrolides, from methanol solutions using an internal standard [9].

The structural characterization of macrolides by mass spectrometry has proven to be an ongoing analytical challenge because of the low number of diagnostic fragment ions in the CAD spectra of the protonated molecules. For example, protonated macrolides typically lose water molecules in succession as the dominant dissociation pathways [5]. Another recognized feature of the dissociation behavior of protonated mac- rolides is their tendency to lose their sugar functional groups while the large, flexible macrolide ring remains largely intact. Confirmation of the type of sugars or other substituents at carbons 3, 5, and 11 (Figure 1) is a key issue in the characterization of new analogs. The use of other activation and ionization methods may provide an avenue for addressing the challenging structural characterization problems associated with the analysis of macrolides.

In the present study, CAD and IRMPD are used to characterize three macrolide compounds and four precursors of an in vitro total synthesis of erythromycin B (Figure 1). Lithium cationization was also evaluated as a potential means of providing complementary structural information obtained from fragmentation. Alkali metal cationization in general has been explored in 

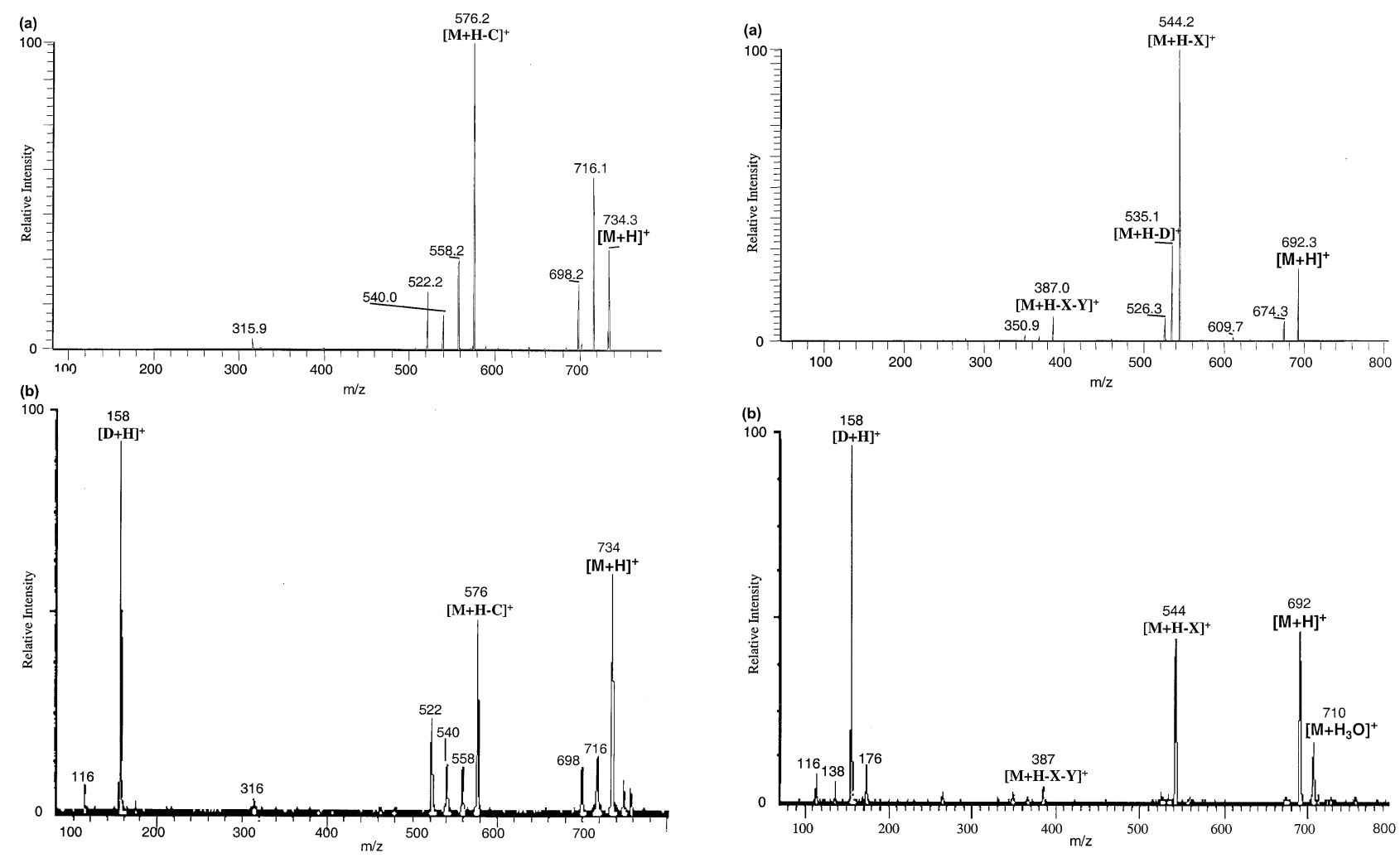

Figure 2. (a) CAD and (b) IRMPD of protonated erythromycin A.

Figure 3. (a) CAD and (b) IRMPD of protonated SP3.

recent years as an alternative to conventional protonation in electrospray ionization and as a means to change the sites of charge localization and promote different fragmentation processes [10-15]. In this report, the fragmentation promoted by CAD and IRMPD methods (including multi-stage tandem mass spectrometry $\left.\left[\mathrm{MS}^{n}\right]\right)$ is compared, along with an evaluation of the diagnostic utility of the fragmentation patterns obtained from the protonated versus lithium-cationized macrolides. A focal point was to determine the best manner for confirming the substituents (i.e., protecting groups and/or sugars for the synthetic precursors) present in the macrolides that would allow confident identification of the structures.

Infrared multiphoton dissociation has been shown to be a viable alternative to CAD for probing molecular structures in trapping instruments [16-29]. In some cases, IRMPD proves to be more efficient than CAD, making it more suitable for $\mathrm{MS}^{n}$ experiments. This advantage results from the fact that IRMPD does not appreciably alter the kinetic energy or stable orbits of the trapped ions. Collisional techniques, however, may lead to ion scattering during energetic collisions intended to excite them internally. Furthermore, in quadrupole ion traps, IRMPD is effective regardless of the trapping potential applied to the ring electrode. Thus, the low-mass cut-off can be maintained at a sufficiently low level that fragments over a wide mass range can be stored and detected. For example, the most effective
CAD conditions typically allow trapping of fragment ions that have mass-to-charge values that are at least $33 \%$ of that of the precursor ion, whereas the IRMPD conditions allow storage of fragment ions that might have mass-to-charge values that are only $10 \%$ of the mass-to-charge of the parent ion. The possibility of performing $\mathrm{MS}^{n}$ by using discreet states of irradiation and isolation can be advantageous for probing genealogies of dissociation while maintaining highly efficient trapping conditions. One potential downside of IRMPD is that activation is less efficient at higher pressures because of the competition from collisional cooling; however, trapping is less effective at lower pressures. A strategy for alleviating this trade-off has been reported recently by the combination of IRMPD with heating of the trap, thus improving energy deposition while maintaining satisfactory trapping efficiency by allowing use of higher pressures [29]. Although not used in the present application because of the naturally high dissociation efficiencies of the erythromycin compounds, heating should offset this drawback of IRMPD for other applications.

\section{Experimental}

Two QIT mass spectrometers with electrospray ionization sources were used. The first instrument was an in-house built QIT system that utilized modified Finnigan ITD electronics and software with an ESI source 
Table 1. CAD and IRMPD data for protonated molecules

\begin{tabular}{|c|c|c|c|c|c|}
\hline Compound & $\begin{array}{l}\text { Parent } \\
(\mathrm{m} / \mathrm{z})\end{array}$ & $\begin{array}{l}\text { Fragments } \\
\qquad(\mathrm{m} / \mathrm{z})\end{array}$ & $\begin{array}{l}\text { Neutral } \\
\text { loss }\end{array}$ & $\begin{array}{l}\text { CAD Results } \\
\text { Percent }\end{array}$ & $\begin{array}{l}\text { IRMPD Results } \\
\text { Percent }\end{array}$ \\
\hline \multirow[t]{9}{*}{ Erythromycin A } & 734 & 716 & 18 & $24 \%$ & $6 \%$ \\
\hline & & 698 & 36 & $9 \%$ & $6 \%$ \\
\hline & & 576 & 158 & $41 \%$ & $21 \%$ \\
\hline & & 558 & 176 & $11 \%$ & $6 \%$ \\
\hline & & 540 & 194 & $5 \%$ & $6 \%$ \\
\hline & & 522 & 212 & $8 \%$ & $10 \%$ \\
\hline & & 316 & 418 & $2 \%$ & $2 \%$ \\
\hline & & 158 & 576 & - & $40 \%$ \\
\hline & & 116 & 620 & - & $3 \%$ \\
\hline \multirow[t]{7}{*}{ Erythromycin B } & 718 & 700 & 18 & $38 \%$ & $12 \%$ \\
\hline & & 560 & 158 & $22 \%$ & $11 \%$ \\
\hline & & 542 & 176 & $10 \%$ & $8 \%$ \\
\hline & & 524 & 194 & $27 \%$ & $57 \%$ \\
\hline & & 316 & 402 & $3 \%$ & $1 \%$ \\
\hline & & 158 & 560 & - & $10 \%$ \\
\hline & & 116 & 604 & - & $1 \%$ \\
\hline \multirow[t]{8}{*}{ Oleandomycin } & 688 & 616 & 72 & $2 \%$ & - \\
\hline & & 544 & 144 & $86 \%$ & $42 \%$ \\
\hline & & 387 & 301 & $1 \%$ & - \\
\hline & & 369 & 319 & $2 \%$ & - \\
\hline & & 351 & 337 & $1 \%$ & - \\
\hline & & 302 & 386 & $8 \%$ & - \\
\hline & & 158 & 530 & - & $54 \%$ \\
\hline & & 116 & 572 & - & $4 \%$ \\
\hline \multirow[t]{7}{*}{ SP1 } & 720 & 702 & 128 & $1 \%$ & - \\
\hline & & 562 & 158 & $97 \%$ & $42 \%$ \\
\hline & & 544 & 176 & $1 \%$ & $2 \%$ \\
\hline & & 316 & 404 & $1 \%$ & $1 \%$ \\
\hline & & 176 & 544 & - & $2 \%$ \\
\hline & & 158 & 562 & - & $49 \%$ \\
\hline & & 116 & 606 & - & $4 \%$ \\
\hline \multirow[t]{10}{*}{ SP2 } & 562 & 544 & 18 & $62 \%$ & $3 \%$ \\
\hline & & 405 & 157 & $8 \%$ & - \\
\hline & & 387 & 175 & $5 \%$ & $1 \%$ \\
\hline & & 369 & 193 & $2 \%$ & - \\
\hline & & 351 & 211 & $3 \%$ & $2 \%$ \\
\hline & & 267 & 295 & $6 \%$ & $2 \%$ \\
\hline & & 176 & 386 & $2 \%$ & $3 \%$ \\
\hline & & 158 & 404 & $12 \%$ & $75 \%$ \\
\hline & & 138 & 424 & - & $2 \%$ \\
\hline & & 116 & 448 & - & $12 \%$ \\
\hline \multirow[t]{14}{*}{ SP3 } & 692 & 674 & 18 & $4 \%$ & $1 \%$ \\
\hline & & 610 & 82 & $1 \%$ & - \\
\hline & & 544 & 148 & $62 \%$ & $24 \%$ \\
\hline & & 535 & 157 & $20 \%$ & $1 \%$ \\
\hline & & 526 & 166 & $5 \%$ & $2 \%$ \\
\hline & & 517 & 175 & $<1 \%$ & $<1 \%$ \\
\hline & & 387 & 305 & $5 \%$ & $2 \%$ \\
\hline & & 369 & 323 & $1 \%$ & $1 \%$ \\
\hline & & 351 & 341 & $1 \%$ & $2 \%$ \\
\hline & & 267 & 425 & $1 \%$ & $2 \%$ \\
\hline & & 176 & 516 & - & $6 \%$ \\
\hline & & 158 & 534 & - & $53 \%$ \\
\hline & & 138 & 554 & - & $3 \%$ \\
\hline & & 116 & 578 & - & $4 \%$ \\
\hline \multirow[t]{2}{*}{ SP4 } & 653 & 635 & 18 & $1 \%$ & $1 \%$ \\
\hline & & 517 & 136 & $64 \%$ & $13 \%$ \\
\hline
\end{tabular}


Table 1. Continued

\begin{tabular}{|c|c|c|c|c|c|}
\hline Compound & $\begin{array}{l}\text { Parent } \\
(\mathrm{m} / \mathrm{z})\end{array}$ & $\begin{array}{l}\text { Fragments } \\
\qquad(\mathrm{m} / \mathrm{z})\end{array}$ & $\begin{array}{c}\text { Neutral } \\
\text { loss }\end{array}$ & $\begin{array}{c}\text { CAD Results } \\
\text { Percent }\end{array}$ & $\begin{array}{l}\text { IRMPD Results } \\
\text { Percent }\end{array}$ \\
\hline & & 505 & 148 & $3 \%$ & $1 \%$ \\
\hline & & 487 & 166 & $2 \%$ & $4 \%$ \\
\hline & & 369 & 284 & $13 \%$ & $13 \%$ \\
\hline & & 351 & 302 & $13 \%$ & $29 \%$ \\
\hline & & 333 & 320 & $2 \%$ & $9 \%$ \\
\hline & & - & 387 & - & $5 \%$ \\
\hline & & 241 & 412 & $2 \%$ & $7 \%$ \\
\hline & & - & 429 & - & $9 \%$ \\
\hline & & - & 533 & - & $9 \%$ \\
\hline
\end{tabular}

and interface modeled after the Oak Ridge National Laboratory design [30]. A stored waveform inverse Fourier transform (SWIFT) system controlled by TTL triggers in the scan function was used for resonant ejection and was described in detail previously [17]. IRMPD experiments were performed with a model 575 Apollo (Apollo Lasers, Chatsworth, CA) continuouswave $\mathrm{CO}_{2}$ laser used in conjunction with a Uniblitz shutter (Vincent Associates, Rochester, NY). The center of the trap was irradiated through a ZnSe window (II-VI Incorporated Saxonburg, PA) in the vacuum chamber aligned with a $6 \mathrm{~mm}$ hole drilled radially in the ring electrode [17]. The IRMPD laser irradiation was varied between 1 and $1000 \mathrm{~ms}$ as needed at a flux of 45 $\mathrm{W} / \mathrm{cm}^{2}$.

For the IRMPD experiments, solutions of each macrolide were made up in methanol at concentrations of $5 \times 10^{-4} \mathrm{M}$. For lithium complexation experiments, equal volumes of $5 \times 10^{-3} \mathrm{M}$ metal salt solution and aminoglycoside solution were combined to provide a 10 times metal excess. Electrospray of the solutions was undertaken at a needle voltage of $4.0 \mathrm{kV}$ and a flow rate of $3 \mathrm{uL} / \mathrm{min}$. The chamber pressure was typically 0.1 mtorr (uncorrected) based on the mixture of air and solvent admitted through the ESI orifice; addition of an auxiliary bath gas was unnecessary. Note that this

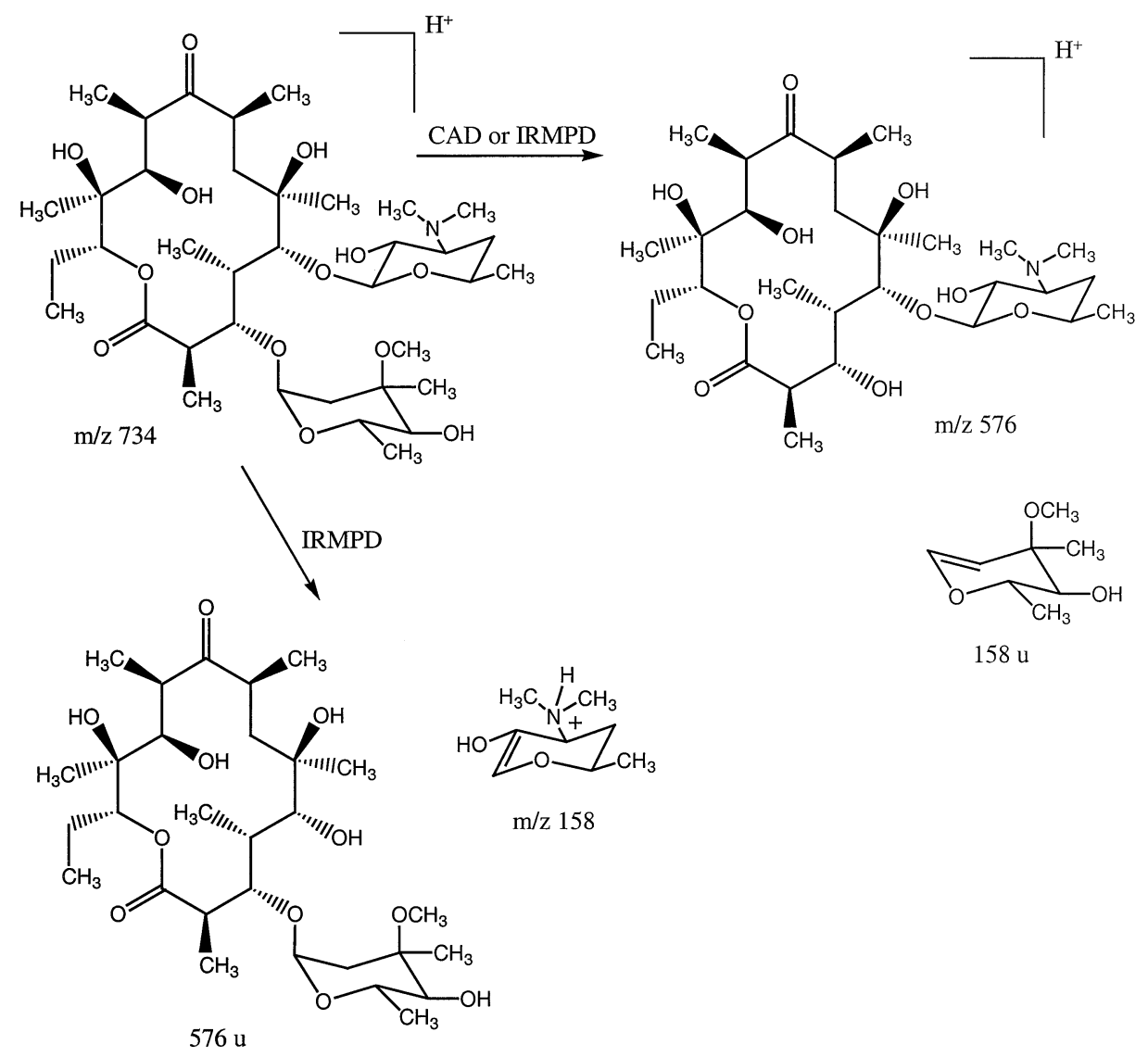

Scheme 1 

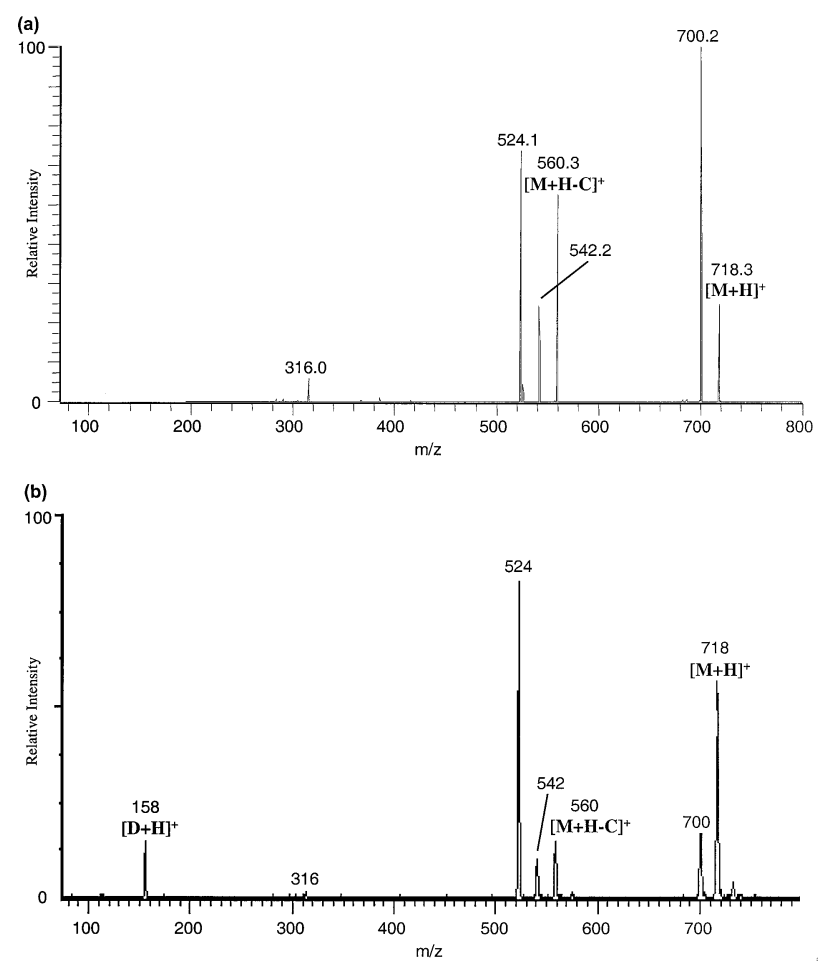

Figure 4. (a) CAD and (b) IRMPD of protonated erythromycin B.

pressure is so high that helium is never routinely added to this system, even for CAD experiments. This is clearly an artifact of the ESI interface design, and other ESI/quadrupole ion trap systems typically require the use of helium to improve trapping efficiencies.

CAD experiments were performed on a Finnigan LCQ-Duo using the Xcalibur (Finnigan, San Jose, CA) software package and the electrospray source. The solutions utilized were the same as those previously described, diluted by a factor of ten. The pressure was maintained at nominally $5 \times 10^{-6}$ torr with helium in the absence of ESI. For ESI experiments, the sample flow rate was $3 \mu \mathrm{L} / \mathrm{min}$, and the pressure in the analyzer region was then nominally $1 \times 10^{-5}$ torr with helium buffer gas. Ionization and trapping conditions were optimized for each of the macrolides; re-tuning for individual samples was seldom necessary.

Erythromycin A and B and oleandomycin were obtained from Sigma Chemical (St. Louis, MO). SP1 and SP2 were degraded from natural erythromycin B [31]. SP3 [32] and SP4 [33] were prepared by synthetic methods.

\section{Results and Discussion}

\section{Protonated Macrolides and Analogs}

For simplicity in discussing the four synthetic precursors, each is assigned an abbreviated designation: Synthetic precursor (SP1-4), as shown in Figure 1. Examples of the CAD and IRMPD spectra for two of the protonated macrolides are shown in Figures 2 and 3 for erythromycin A and SP3. The CAD data was obtained by using the commercial LCQ instrument, whereas the IRMPD data was obtained with the home-built ion trap instrument because it was felt that the CAD data from the LCQ instrument would be more useful to the growing number of users of commercial ion trap instruments. Thus, in this report the best CAD data (from the LCQ ion trap) is compared to the best IRMPD data available (from the home-built instrument). Both CAD and IRMPD data for all seven protonated compounds are summarized in Table 1. The most prevalent fragmentation pathways include dehydration (for four of the macrolides) and loss of the cladinose sugar (for the four that possess the cladinose moiety) (Scheme 1). In the IRMPD spectra, the formation of a characteristic desosamine ion at $\mathrm{m} / \mathrm{z} 158$ for protonated erythromycin A and B, SP1, SP2, and SP3 is also significant (Scheme 1). This fragment ion is not observed in the analogous CAD spectra because the mass is too low to be trapped efficiently under the conditions needed for activation of the high mass precursors. The schemes presented in this work offer proposed fragment ion structures that are consistent with genealogical pathways and secondary fragmentation information obtained from multi-stage IRMPD $\left(\mathrm{MS}^{n}\right)$ experiments, as discussed later.

The IRMPD and CAD spectra of protonated erythromycin A have comparable signal intensities, dissociation efficiencies, and fragment ions (Figure 2), with the notable exception of the absence of the characteristic desosamine ion at $\mathrm{m} / \mathrm{z} 158$ in the CAD spectrum. Both spectra show two water losses, loss of the cladinose sugar (-158 a $\mu$, formation of $m / z 576)$, and further water losses from the macrolide ring. Protonated erythromycin B displays one less loss of water than erythromycin A in both the IRMPD and CAD spectra (Figure 4 ), implying that the C-12 hydroxyl accounts for this extra step of dehydration in protonated erythromycin A. Protonated oleandomycin dissociates by the loss of the hexapyranose moiety in both the IRMPD and CAD spectra (formation of $\mathrm{m} / \mathrm{z} 544$ ), loss of both sugars (formation of $m / z 387$ ), and by formation of the desosamine ion $(\mathrm{m} / \mathrm{z} 158)$ (IRMPD only). The absence of dehydration, a loss that was significant for both protonated erythromycin A and B, is accounted for by the lack of a hydroxyl group at C-6 [5]. Apparently the C-11 hydroxyl group is not a viable route for dehydration in these macrolides.

Protonated SP1 (with a C-9 hydroxyl instead of a carbonyl) and SP4 (in which the C-9 oxygen is involved in binding to the trimethylbenzyl protecting group) exhibit virtually no water loss in either the CAD or IRMPD spectra, corroborating the C-6/C-9 oxonium formation mechanism proposed by Gates et al. [4], in which the carbonyl oxygen at C-9 was involved in dehydration. The dissociation spectrum of protonated SP3 displays a small signal corresponding to water loss; the presence of a new hydroxyl group at C-3 likely accounts for this fragmentation pathway. Protonated 
(a)

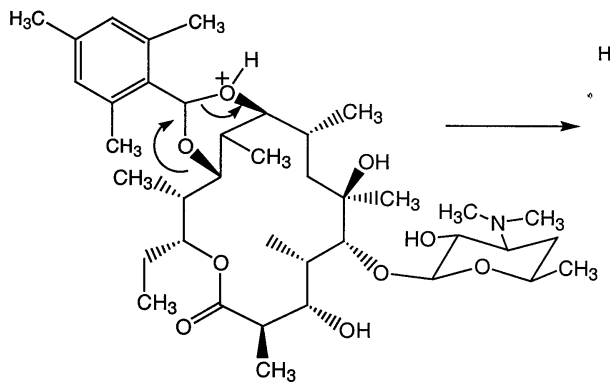

$[\mathrm{SP} 3+\mathrm{H}]^{+}$<smiles>Cc1cc(C)c(C=O)c(C)c1</smiles>

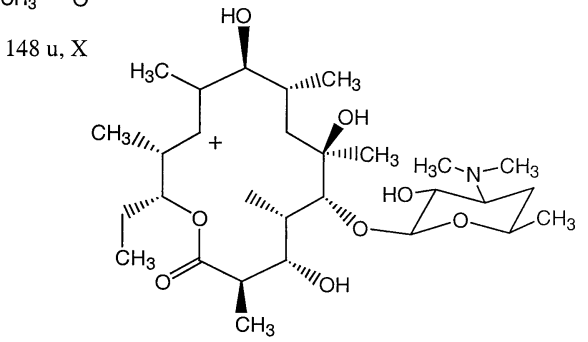

$\mathrm{m} / \mathrm{z} 544$

(b)

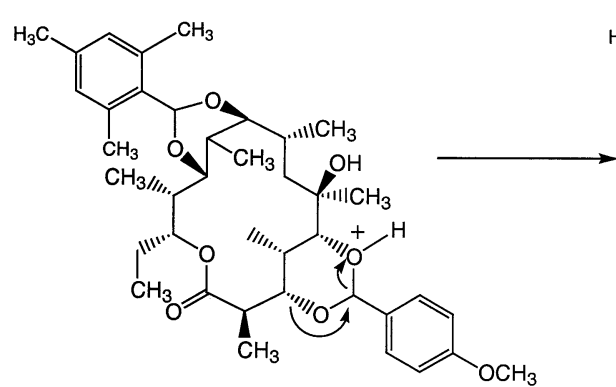

$[\mathrm{SP} 4+\mathrm{H}]^{+}$
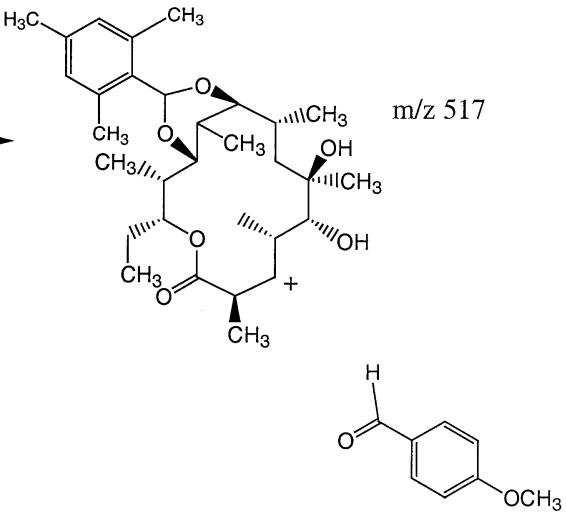

$136 \mathrm{u}, \mathrm{Y}$

Scheme 2

SP2 undergoes extensive dehydration, thus confirming that the presence of the C-3 hydroxyl group promotes dehydration even in the absence of the C-9 carbonyl. Loss of desosamine as a neutral is a significant pathway only for protonated SP3, the only compound lacking the less basic cladinose moiety and in which the C-9 and $\mathrm{C}-11$ oxygens bridge a trimethylbenzyl substituent, thus suppressing the typical dehydration pathway.

SP3 and SP4 are interesting cases because both lack the cladinose sugar, and the active C-9 oxygen (which is key for the dominant dehydration step in the other macrolides) is bound to a trimethylbenzyl substituent. In addition, SP4 lacks the desosamine moiety, and the C-5 and C-3 oxygens are bound to a p-methoxybenzyl substituent. For protonated SP3, the loss of the trimethylbenzyl substituent is a dominant pathway, despite the fact that this substituent is connected to the macrolide ring by two carbon-oxygen bonds. One route that accounts for this loss is shown in Scheme 2a, but the site of the ionizing proton has not been confirmed. For protonated SP4, the elimination of the trimethylbenzyl substituent is not observed; instead, the loss of the other substituent is dominant (Scheme $\mathbf{2 b}$ ).

Other than the notable absence of the lower mass fragment ions in the CAD spectra that are prominent in the IRMPD spectra, the CAD and IRMPD spectra are qualitatively similar. In both the IRMPD and CAD spectra, cleavages of the macrolide ring are absent or insignificant. Moreover, neither IRMPD nor CAD provide sufficient diagnostic fragment ions to confirm the protecting groups at each position of SP4. These latter two shortcomings prompted our interest in lithium cationization as an alternative to protonation to produce precursor ions that potentially would give complementary structural information upon activation.

\section{Lithium Cationized Macrolides}

Production of lithium-cationized complexes only required the addition of a lithium salt to the solutions containing the macrolides, so it is an easy way to create ions that may give complementary or more diagnostic 

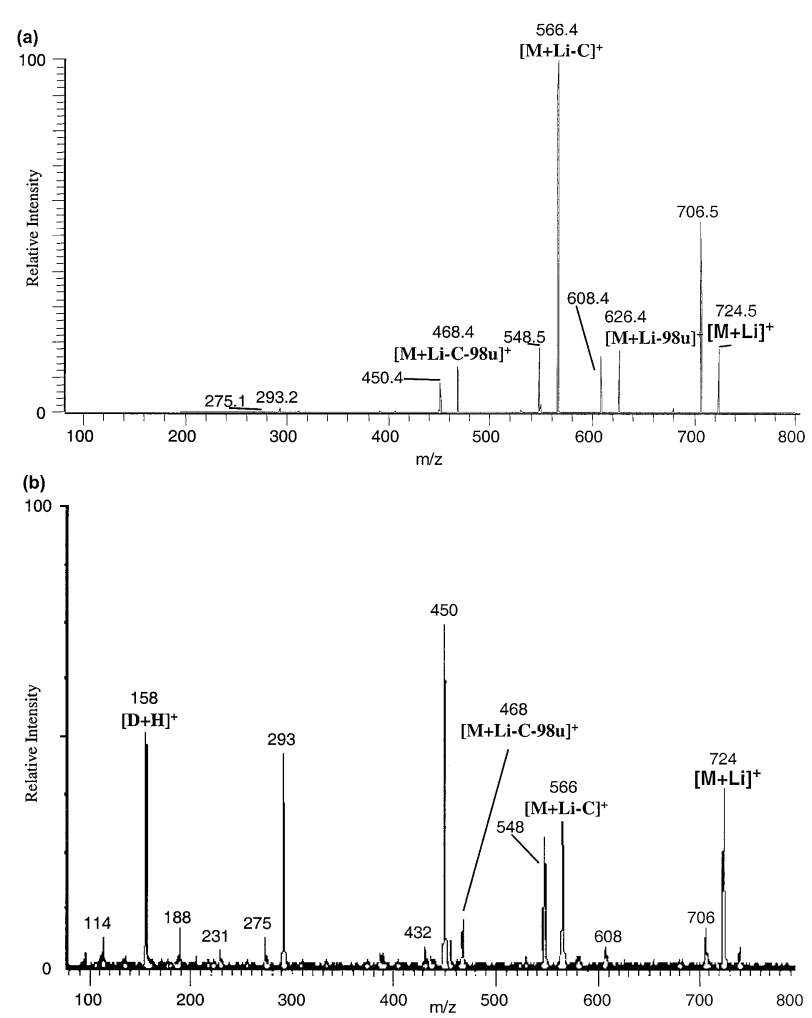

Figure 5. (a) CAD and (b) IRMPD of lithium-cationized erythromycin $B$.

structural information compared to that obtained for protonated molecules. While overall signal intensities were of the same order of magnitude for either ionization technique, the alkali metal complexes tended to produce more fragments than the protonated counterparts upon CAD or IRMPD. Examples of the fragmentation patterns obtained for the lithium-cationized species are shown for erythromycin B (Figure 5) and SP4 (Figure 6), and all of the IRMPD and CAD data is summarized in Table 2.

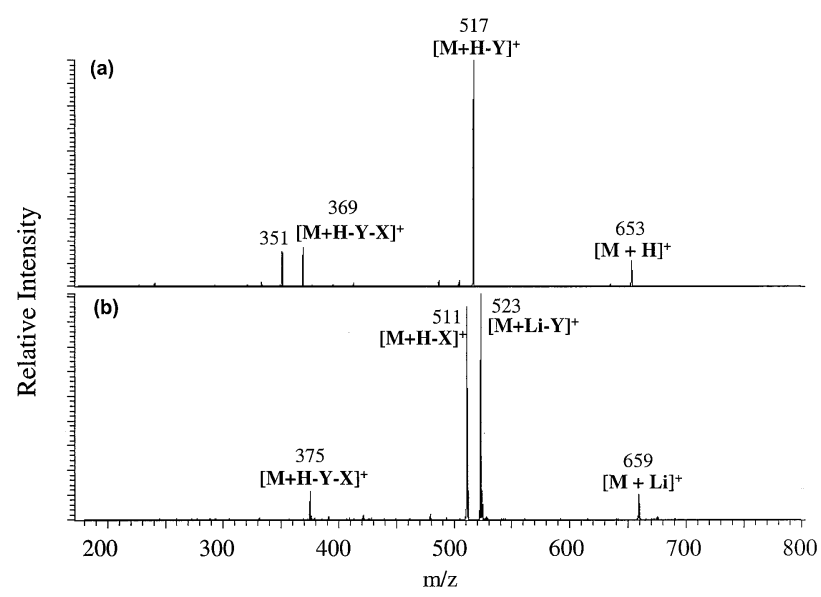

Figure 6. CAD of (a) protonated and (b) lithium-cationized SP4.
There are three notable changes in the dissociation pattern of lithium-cationized erythromycin A compared to that of protonated erythromycin A. First, dehydration is generally limited to a single water loss instead of the two or three seen for protonated erythromycin A. In addition, two new diagnostic fragment ions are observed for lithium-cationized erythromycin $\mathrm{A}$, one at $\mathrm{m} / \mathrm{z} 626$ and one at $\mathrm{m} / \mathrm{z} 608$. A pathway rationalizing the loss of $114 \mathrm{u}$ is shown in Scheme 3, and clearly cleavages of the macrolide ring are required for this fragmentation pathway, a type of process notably absent for the protonated species. Presumably this type of process also accounts for the loss of $132 \mathrm{u}$, which requires the loss of one water molecule in conjunction with the loss of $114 \mathrm{u}$. Cleavages of the macrolide ring were not observed for the protonated species, suggesting that the lithium cationization process substantially changes the activation/dissociation processes of the macrolides. The macrolide cleavage pathways are somewhat more significant for lithium-cationized erythromycin B and oleandomycin in which the losses of $98 \mathrm{u}$ or $116 \mathrm{u}$ for erythromycin B and loss of $84 \mathrm{u}$ for oleandomycin are analogous to those observed for erythromycin A. The mass shifts in these neutral losses compared to those observed for lithium-cationized erythromycin A are accounted for by the absence of the C-12 hydroxyl group in erythromycin B (difference of $16 \mathrm{u}$ ) and the lack of the C-12 hydroxy group and C-13 methylene group in oleandomycin (difference of $30 \mathrm{u}$ ). The loss of $84 \mathrm{u}$ does not occur in conjunction with dehydration for lithium-cationized oleandomycin presumably because of the absence of the C-6 hydroxyl group, as noted earlier for the dissociation of protonated oleandomycin. For lithium-cationized erythromycin A and B, additional new fragment ions at $\mathrm{m} / \mathrm{z} 450$ and 468 indicate that the macrolide ring cleavage illustrated in Scheme 3 may also occur in conjunction with the standard loss of the cladinose ring. In fact, for both lithium-cationized erythromycin A and B, a new fragment ion at $\mathrm{m} / \mathrm{z} 293$ appears, attributed to loss of desosamine $(157 \mathrm{u})$ in combination with the loss of the cladinose moiety and the diagnostic macrolide ring cleavage. (This fragment ion is only significant in the IRMPD spectra.) This combination of neutral losses is supported by multistage IRMPD $\left(\mathrm{MS}^{n}\right)$ experiments. For lithium-cationized oleandomycin, the loss of $84 \mathrm{u}$ may occur in conjunction with the loss of the hexapyranose moiety. A new fragmentation pathway that emerges for lithium-cationized oleandomycin is the loss of formaldehyde, a process that apparently involves the epoxide moiety at the C-8 position. This simple loss, not observed for protonated oleandomycin, provides a key way to confirm the epoxide substituent.

Both protonated and lithium-cationized SP1 give one major fragment, loss of cladinose. Of all the macrolides analyzed, SP1 shows the fewest differences in the fragmentation patterns of the protonated and lithiumcationized species. Two new fragment ions that emerge for the lithium-cationized species are the loss of cladi- 
Table 2. CAD and IRMPD data for lithium-cationized macrolides

\begin{tabular}{|c|c|c|c|c|c|}
\hline Compound & Parent $(m / z)$ & Fragment $(m / z)$ & Neutral loss & $\begin{array}{l}\text { CAD Results } \\
\text { Percent }\end{array}$ & $\begin{array}{l}\text { IRMPD Results } \\
\text { Percent }\end{array}$ \\
\hline \multirow[t]{10}{*}{ Erythromycin A } & 740 & 722 & 18 & $37 \%$ & $7 \%$ \\
\hline & & 626 & 114 & $2 \%$ & - \\
\hline & & 608 & 132 & $2 \%$ & - \\
\hline & & 582 & 158 & $44 \%$ & $16 \%$ \\
\hline & & 564 & 176 & $13 \%$ & $37 \%$ \\
\hline & & 546 & 194 & $<1 \%$ & $5 \%$ \\
\hline & & 468 & 272 & $1 \%$ & - \\
\hline & & 450 & 290 & $1 \%$ & $13 \%$ \\
\hline & & 293 & 447 & $<1 \%$ & $12 \%$ \\
\hline & & 158 & 582 & - & $10 \%$ \\
\hline \multirow[t]{12}{*}{ Erythromycin B } & 724 & 706 & 18 & $23 \%$ & $3 \%$ \\
\hline & & 706 & 18 & $23 \%$ & $3 \%$ \\
\hline & & 626 & 98 & $8 \%$ & - \\
\hline & & 608 & 116 & $7 \%$ & $2 \%$ \\
\hline & & 566 & 158 & $44 \%$ & $12 \%$ \\
\hline & & 548 & 176 & $8 \%$ & $10 \%$ \\
\hline & & 468 & 256 & $6 \%$ & $4 \%$ \\
\hline & & 450 & 274 & $4 \%$ & $27 \%$ \\
\hline & & 293 & 431 & $<1 \%$ & $17 \%$ \\
\hline & & 275 & 449 & $<1 \%$ & $3 \%$ \\
\hline & & 158 & 566 & - & $19 \%$ \\
\hline & & 116 & 610 & - & $3 \%$ \\
\hline \multirow[t]{11}{*}{ Oleandomycin } & 694 & 664 & 30 & $13 \%$ & $1 \%$ \\
\hline & & 610 & 84 & $7 \%$ & $1 \%$ \\
\hline & & 550 & 144 & $69 \%$ & 27 \\
\hline & & 537 & 157 & $2 \%$ & $3 \%$ \\
\hline & & 532 & 162 & $3 \%$ & $1 \%$ \\
\hline & & 466 & 228 & $4 \%$ & $5 \%$ \\
\hline & & 393 & 301 & $1 \%$ & $1 \%$ \\
\hline & & 375 & 319 & $1 \%$ & $1 \%$ \\
\hline & & 309 & 385 & - & $1 \%$ \\
\hline & & 158 & 536 & - & $55 \%$ \\
\hline & & 116 & 578 & - & $4 \%$ \\
\hline \multirow[t]{7}{*}{ SP1 } & 726 & 568 & 158 & $96 \%$ & $58 \%$ \\
\hline & & 506 & 220 & $2 \%$ & $3 \%$ \\
\hline & & 440 & 286 & $<1 \%$ & $2 \%$ \\
\hline & & 411 & 315 & $2 \%$ & $4 \%$ \\
\hline & & 176 & 550 & - & $1 \%$ \\
\hline & & 158 & 568 & - & $26 \%$ \\
\hline & & 116 & 612 & - & $6 \%$ \\
\hline \multirow[t]{10}{*}{ SP2 } & 568 & 550 & 18 & $5 \%$ & No Data \\
\hline & & 523 & 45 & 3 & \\
\hline & & 506 & 62 & $33 \%$ & \\
\hline & & 498 & 70 & 3 & \\
\hline & & 494 & 74 & $4 \%$ & \\
\hline & & 453 & 115 & $3 \%$ & \\
\hline & & 440 & 128 & $8 \%$ & \\
\hline & & 411 & 157 & $31 \%$ & \\
\hline & & 393 & 175 & $8 \%$ & \\
\hline & & 377 & 193 & $2 \%$ & \\
\hline \multirow[t]{8}{*}{ SP3 } & 698 & 680 & 18 & $22 \%$ & No Data \\
\hline & & 636 & 62 & $12 \%$ & \\
\hline & & 624 & 74 & $4 \%$ & \\
\hline & & 582 & 116 & $3 \%$ & \\
\hline & & 550 & 148 & $27 \%$ & \\
\hline & & 541 & 157 & $6 \%$ & \\
\hline & & 530 & 168 & $7 \%$ & \\
\hline & & & & & (continued) \\
\hline
\end{tabular}


Table 2. Continued

\begin{tabular}{|c|c|c|c|c|c|}
\hline Compound & Parent $(\mathrm{m} / \mathrm{z})$ & Fragment $(\mathrm{m} / \mathrm{z})$ & Neutral loss & $\begin{array}{l}\text { CAD Results } \\
\text { Percent }\end{array}$ & $\begin{array}{c}\text { IRMPD Results } \\
\text { Percent }\end{array}$ \\
\hline & & 523 & 175 & $14 \%$ & \\
\hline & & 450 & 248 & $2 \%$ & \\
\hline & & 393 & 305 & $3 \%$ & \\
\hline \multirow[t]{9}{*}{ SP4 } & 659 & 641 & 18 & $<1 \%$ & $1 \%$ \\
\hline & & 523 & 136 & $45 \%$ & $16 \%$ \\
\hline & & 511 & 148 & $44 \%$ & $22 \%$ \\
\hline & & 479 & 180 & $4 \%$ & $2 \%$ \\
\hline & & 375 & 284 & $5 \%$ & $11 \%$ \\
\hline & & 293 & 366 & $1 \%$ & $8 \%$ \\
\hline & & 277 & 382 & $<1 \%$ & $10 \%$ \\
\hline & & 118 & 541 & - & $23 \%$ \\
\hline & & 106 & 553 & - & $7 \%$ \\
\hline
\end{tabular}

nose in conjunction with either the loss of $62 \mathrm{u}$, giving a product at $m / z 506$, or the loss of $128 \mathrm{u}$, giving a fragment ion at $m / z 440$. These eliminations of 62 or $128 \mathrm{u}$ are highly diagnostic losses discussed later for lithium-cationized SP2 and SP3, thus representing very characteristic fragmentation pathways for these three macrolides.

The fragmentation pattern of lithium-cationized SP2 is much richer than that of the protonated species, which predominantly lost water and/or desosamine. Three new fragmentation pathways are the losses of $62 \mathrm{u}, 70 \mathrm{u}$, or $128 \mathrm{u}$, which may occur consecutively based on $\mathrm{MS}^{n}$ experiments and involve cleavages of the macrolide ring. Proposed fragments to account for these losses are illustrated in Scheme 4 . The specific site of dehydration is not known. In addition to the same fragmentation processes seen for protonated SP3 (i.e., dehydration, loss of desosamine, loss of the trimethyl benzyl group), lithium cationized SP3 also dissociates by loss of the characteristic $62 \mathrm{u}$ species.

The effect of lithium cationization on the dissociation of SP4 is especially striking, as illustrated by the CAD spectra shown in Figure 6. In addition to the dominant loss of $136 \mathrm{u}$ (the trimethyl benzyl substituent, formation of $m / z 523$ ) that was observed upon dissociation of protonated SP4, the loss of the other substituent, the p-methoxybenzyl group (loss of $148 \mathrm{u}$, formation of $\mathrm{m} / \mathrm{z}$ 511 ), is also evident. These losses are depicted in Scheme 5. In the lithium-containing products shown in Scheme 5, further hydrogen migrations may occur to allow favorable delocalization of the charge and multisite coordination of lithium. The ability to lose either substituent likely relates to the greater delocalization of the lithium ion compared to that of an ionizing proton in the macrolide.

As noted above in the comparison of the IRMPD and

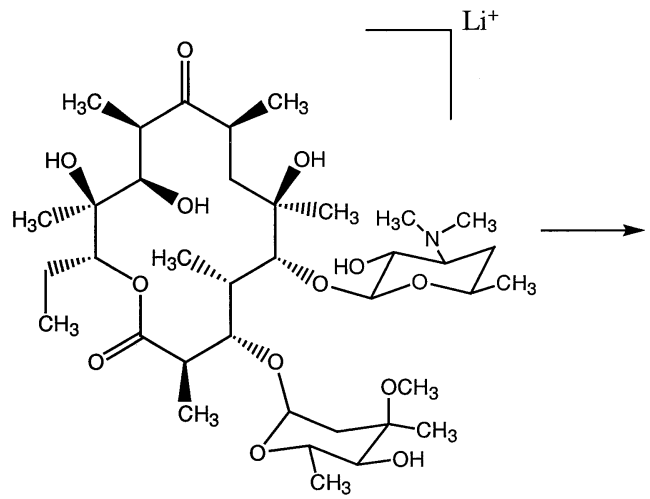

$\mathrm{m} / \mathrm{z} 740$

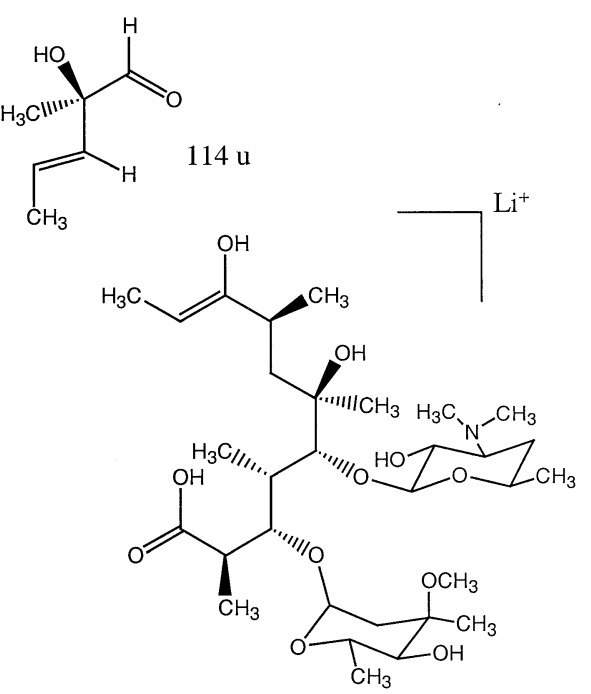

$\mathrm{m} / \mathrm{z} 626$ 


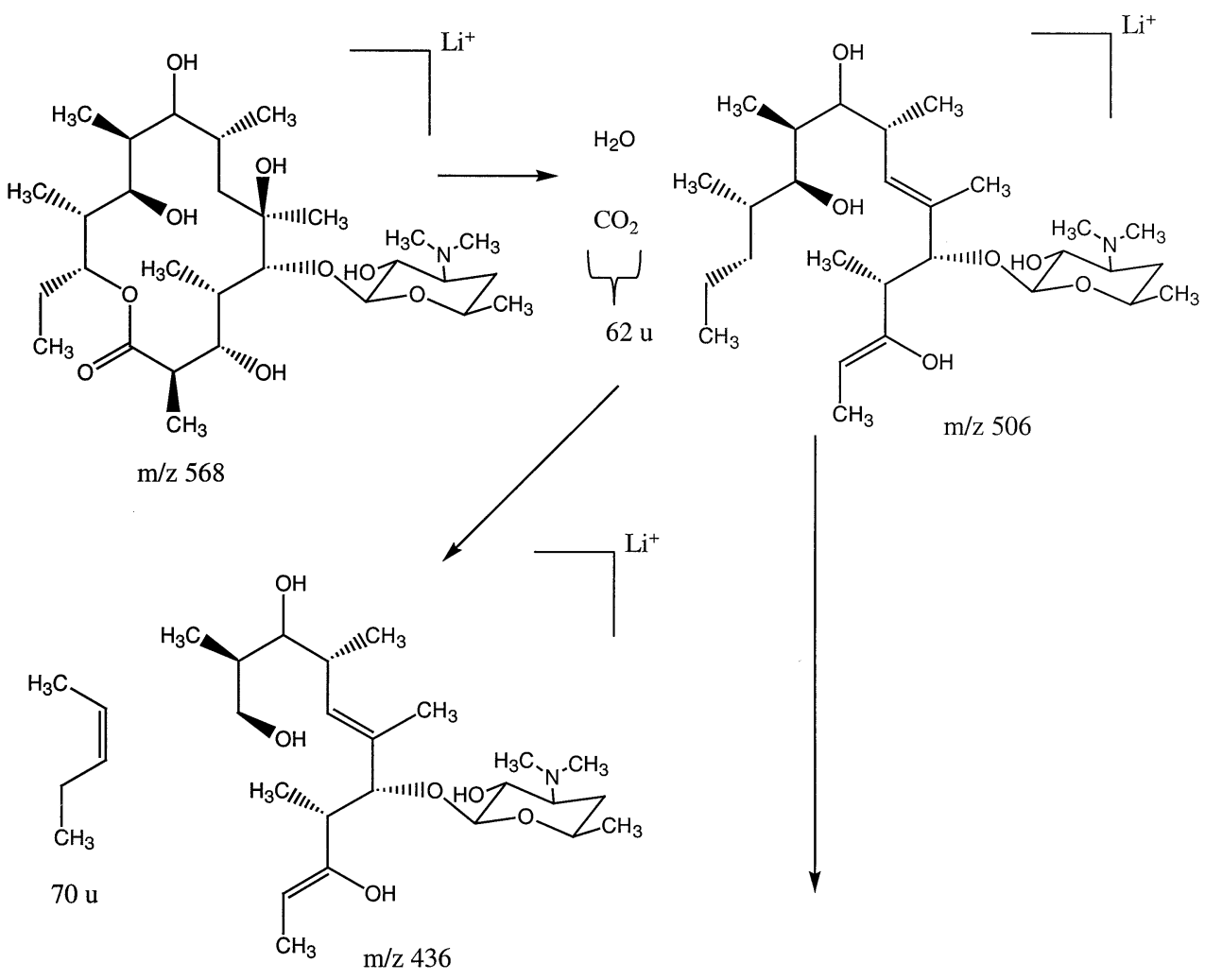

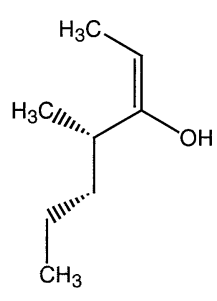

$128 \mathrm{u}$

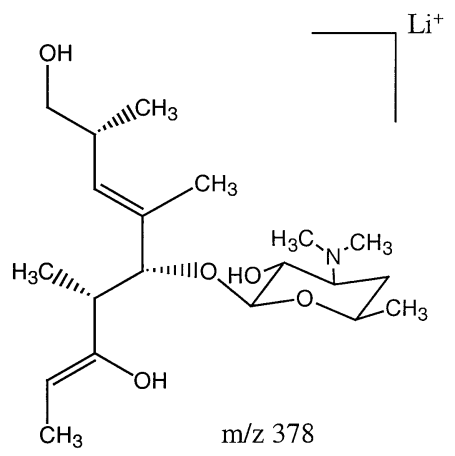

Scheme 4

CAD spectra for the protonated macrolides, the IRMPD spectra for the lithium-cationized compounds also show more intense mid- and lower mass fragment ions, presumably due to the ability to effectively trap these ions because the lower mass storage range is not cut off as in the CAD experiments. Interestingly, the formation of the desosamine ion at $m / z 158$ (refer to Scheme $\mathbf{1}$ for the proposed structure of this ion) is still observed in the IRMPD spectra for the lithium-cationized compounds. IRMPD of lithium-cationized SP2 and SP3 was unsuccessful because of the inadequate ion isolation capability of the in-house IRMPD/ion trap system, a problem that potentially will be corrected by the use of a more advanced arbitrary waveform generator. The poor isolation is not attributed to the IRMPD experiment itself because isolation was similarly poor when attempting CAD experiments for SP2 and SP3.
Time-Variable IRMPD and Multi-Stage IRMPD $\left(M S^{n}\right)$

One way to extend the diagnostic utility of the IRMPD method is to monitor the IRMPD spectra as a function of the irradiation time. The resulting time-resolved data allow selection of the IRMPD conditions for optimization of the fragmentation patterns and give an initial assessment of potential genealogical relationships of the fragment ions. An example of the time-resolved data obtained for one of the protonated macrolides, SP1, is shown in Figure 7. The dominant fragment ion at low activation times is $m / z 562$, resulting from the loss of the cladinose substituent. As the irradiation time increases, these primary fragment ions absorb sufficient photons to dissociate, thus causing a reduction in the intensity of the $m / z 562$ ion and production of $m / z$ 158, the des- 

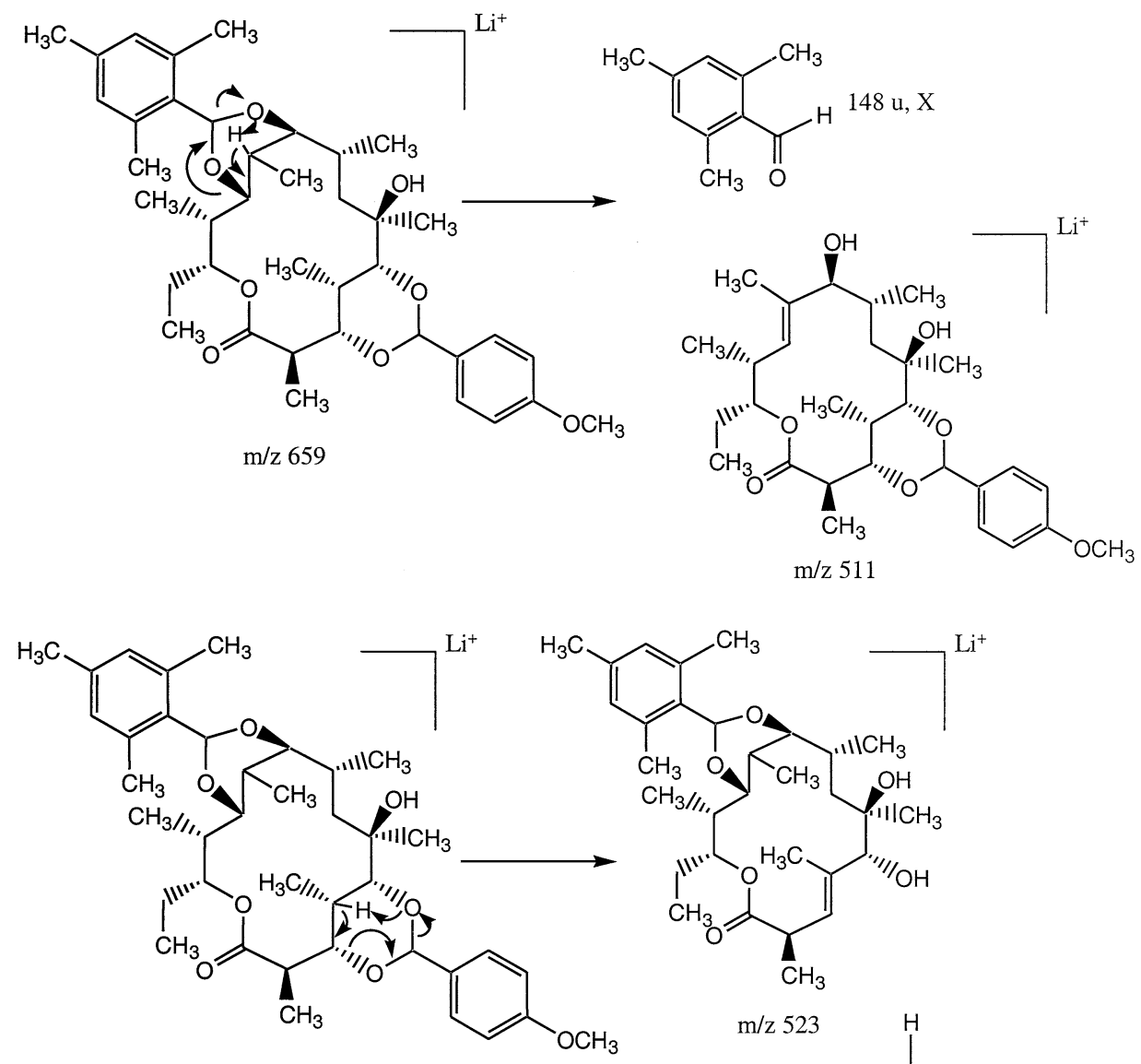

$\mathrm{m} / \mathrm{z} 659$

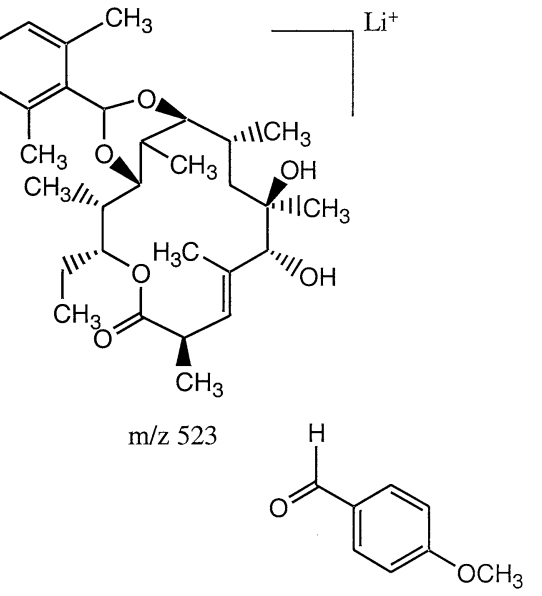

$136 \mathrm{u}, \mathrm{Y}$

Scheme 5

osamine ion. This behavior implies both a genealogical relationship and allows an effective way to tune the IRMPD conditions to optimize the formation of specific fragments for further interrogation.

Discrete stages of isolation and activation give more specific genealogical information than that obtained by time-variable IRMPD or energy-variable CAD. Multistage IRMPD $\left(\mathrm{MS}^{n}\right)$ is particularly efficient because the losses due to ion scattering that may occur with multiple stages of CAD are virtually eliminated. An example

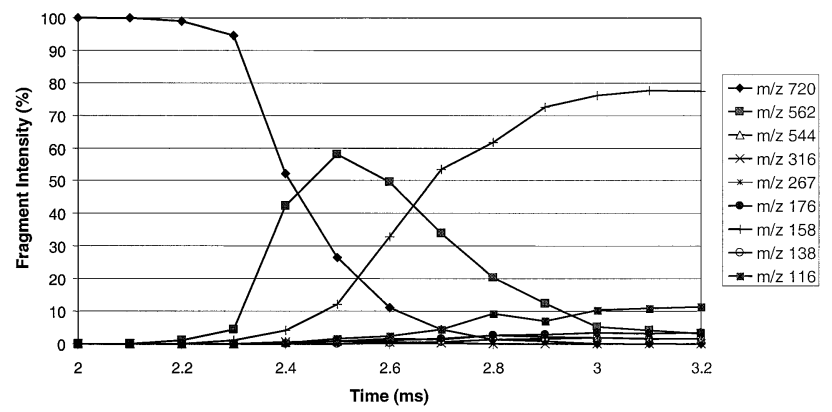

Figure 7. Time-variable IRMPD of protonated SP1. of the utility of multi-stage IRMPD is shown in Figure 8 for protonated erythromycin B. The IRMPD spectrum is shown in Figure 8a, and the major fragments are due to dehydration $(m / z 700)$ or loss of cladinose $(m / z 560)$, or loss of cladinose and one or two units of water $(\mathrm{m} / z 542$ and 524). In formulating mechanisms to account for these pathways and to develop predictions for related analogs, it would be useful to know whether the macrolide dehydrates prior to or after the loss of cladinose and whether all of the primary fragments dissociate further to produce the desosamine ion at $\mathrm{m} / \mathrm{z}$ 158. In Figure 8b, the IRMPD spectrum obtained for the dehydrated macrolide is shown. It dissociates by loss of the cladinose ring, a second water loss, and formation of the desosamine ion at $m / z 158$. Figure $8 \mathrm{c}$ shows that isolation and activation of $m / z 560$, the primary fragment resulting from loss of cladinose from the protonated macrolide, results in dehydration or formation of $m / z$ 158. Isolation of the secondary fragment ion, $m / z$ 542 , indicates that this ion does not dehydrate but instead dissociates to form the desosamine ion. This sequence of IRMPD experiments indicates that all of the primary fragments ultimately may result in the des- 

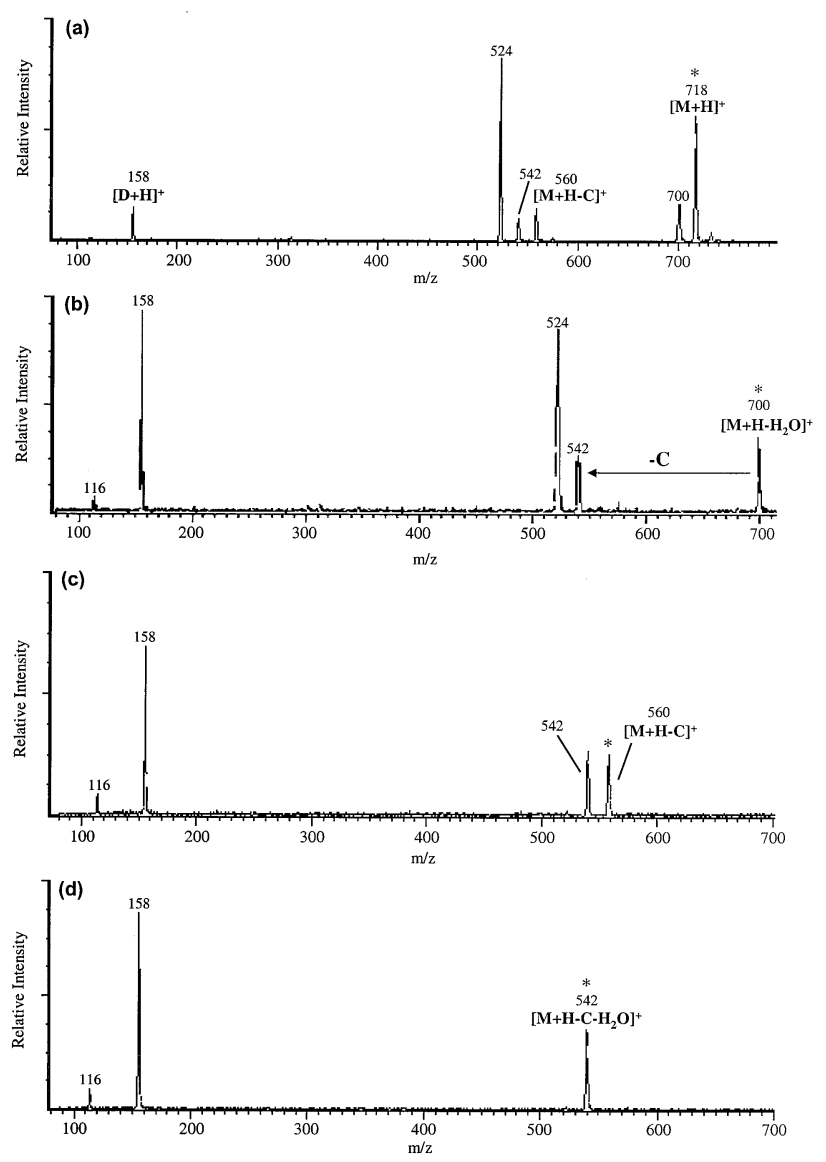

Figure 8. IRMPD mass spectra of protonated erythromycin B. (a) IRMPD of protonated erythromycin B. (b) IRMPD/IRMPD of the fragment ion at $\mathrm{m} / \mathrm{z} 700$ from protonated erythromycin B. (c) IRMPD/IRMPD of the fragment ion at $\mathrm{m} / z 560$ from protonated erythromycin B. (d) IRMPD/IRMPD/IRMPD of the fragment ion at $m / z 542$ from $m / z 560$ from protonated erythromycin B.

osamine ion, that dehydration and loss of cladinose may occur in either order, but that if the protonated macrolide loses the cladinose moiety, it may not undergo two stages of dehydration. The multi-stage IRMPD spectral results are summarized in Table 3.

For protonated erythromycin A, a second stage of IRMPD on the fragment ion at $\mathrm{m} / \mathrm{z} 576$ (due to loss of cladinose) formed upon IRMPD of the protonated macrolide indicates that this fragment ion may undergo up to three steps of dehydration, whereas protonated erythromycin A undergoes only two steps of dehydration. This additional step of dehydration for the $m / z 576$ fragment suggests that the hydroxyl group at the C-3 position (see Scheme 1), involved in a glycosidic bond for protonated erythromycin A, may be key for this process. The multi-stage IRMPD spectra for the fragment ion at $m / z 158$ is identical for both protonated erythromycin A and B.

The IRMPD spectrum of the $\mathrm{m} / \mathrm{z} 562$ fragment from protonated SP1 gives the same dominant fragment ions that are observed for protonated SP1. This suggests that many of the lower mass fragment ions may occur through consecutive dissociation steps after loss of the cladinose sugar. For protonated SP2, a similar behavior is observed, in which IRMPD of $m / z 544$, formed upon dehydration of protonated SP2, gives the same four most dominant fragment ions as observed for IRMPD of protonated SP2. These four ions, $m / z$ 176, 158, 138, and 116 , are all characteristic of the desosamine moiety. Protonated SP3 produced $\mathrm{m} / \mathrm{z} 544$ (loss of the trimethyl benzyl substituent) as the second most dominant fragment ion upon IRMPD. IRMPD of this primary fragment ion again resulted in the ions diagnostic for the desosamine moiety. Upon activation protonated SP4 dissociated by loss of the methoxybenzyl substituent $(136 \mathrm{u})$ as one of the major characteristic pathways. Isolation and IRMPD of this fragment ion $(\mathrm{m} / \mathrm{z}$ 517) predominantly results in the loss of the other substituent, the trimethyl benzyl moiety (148 u), which may occur in conjunction with dehydration.

Multi-stage IRMPD experiments are particularly useful for probing the fragmentation pathways of the lithium-cationized compounds in greater detail because more extensive cleavages of the macrolide ring are involved rather than just simple losses of the substituents or sugars. For example, two of the macrolide ring cleavages that were observed upon IRMPD of lithiumcationized erythromycin A were loss of $114 \mathrm{u}$ (proposed in Scheme 3) or loss of $132 \mathrm{u}$ (presumably loss of $114 \mathrm{u}$ in conjunction with dehydration). IRMPD allows further confirmation of these pathways, as summarized in Table 3. A second stage of IRMPD on $\mathrm{m} / \mathrm{z} 582$ (loss of cladinose) results in the loss of $132 \mathrm{u}$ (formation of $\mathrm{m} / \mathrm{z}$ 450 ) or loss of water (formation of $\mathrm{m} / z$ 564). IRMPD of $\mathrm{m} / \mathrm{z} 450$ results in the loss of the desosamine moiety as the dominant fragment ion (formation of $\mathrm{m} / \mathrm{z} 293$ ). A third stage of IRMPD on $\mathrm{m} / \mathrm{z} 293$ yields the diagnostic loss of $62 \mathrm{u}$ seen for many of the other lithiumcationized compounds (i.e., Scheme 4). This series of IRMPD experiments indicates that the loss of water that occurs in conjunction with the diagnostic macrolide cleavage (loss of $114 \mathrm{u}$ ) may occur either before or after the loss of $114 \mathrm{u}$, and likewise the loss of $114 \mathrm{u}$ may occur before or after the loss of the cladinose moiety. For lithium-cationized erythromycin B, a similar genealogical pattern is observed, with the diagnostic macrolide ring cleavage (loss of $98 \mathrm{u}$ ) occurring before or after dehydration and before or after the loss of cladinose. Multi-stage IRMPD confirms the genealogical relationships illustrated in Scheme 4 for lithium-cationized SP1 and SP2, in which activation of $\mathrm{m} / \mathrm{z} 506$ produces fragment ions at both $\mathrm{m} / \mathrm{z} 436$ and 378 . Loss of the desosamine moiety $(157 \mathrm{u})$ is also possible from $\mathrm{m} / \mathrm{z} 506$. Multi-stage IRMPD of lithium-cationized SP4 confirms that loss of either the trimethyl benzene or methoxybenzene substituent may occur first. In general, the multi-stage IRMPD spectra provide more specific fragmentation information than just a single stage of IRMPD, giving greater diagnostic identification of the macrolides when present in mixtures and allowing construction of self-consistent fragmentation pathways. 
Table 3. Multi-step IRMPD results

\begin{tabular}{|c|c|c|c|c|c|}
\hline $\begin{array}{l}\text { Protonated } \\
\text { compounds } \\
\text { Compound }\end{array}$ & $\begin{array}{l}\text { IRMPD } \\
\text { step }\end{array}$ & $\begin{array}{l}\text { Parent }(\mathrm{m} / \mathrm{z}) \\
\text { or sequence }\end{array}$ & $\begin{array}{l}\text { Fragment } \\
\qquad(\mathrm{m} / \mathrm{z})\end{array}$ & Neutral loss & Percent \\
\hline \multirow[t]{18}{*}{ Erythromycin A } & $1^{\mathrm{a}}$ & 734 & 716 & 18 & $6 \%$ \\
\hline & & & 698 & 36 & $6 \%$ \\
\hline & & & 576 & 158 & $21 \%$ \\
\hline & & & 558 & 176 & $6 \%$ \\
\hline & & & 540 & 194 & $6 \%$ \\
\hline & & & 522 & 212 & $10 \%$ \\
\hline & & & 316 & 418 & $2 \%$ \\
\hline & & & 158 & 576 & $40 \%$ \\
\hline & & & 116 & 618 & $3 \%$ \\
\hline & 2 & $734 \rightarrow 576 \rightarrow$ & 558 & 18 & $6 \%$ \\
\hline & & & 540 & 36 & $7 \%$ \\
\hline & & & 522 & 54 & $7 \%$ \\
\hline & & & 158 & 418 & $72 \%$ \\
\hline & & & 116 & 460 & $8 \%$ \\
\hline & 3 & $734 \rightarrow 576 \rightarrow 158$ & 116 & 42 & $25 \%$ \\
\hline & & & 114 & 44 & $24 \%$ \\
\hline & & & 98 & 60 & $12 \%$ \\
\hline & & & 83 & 75 & $39 \%$ \\
\hline \multirow[t]{22}{*}{ Erythromycin B } & 1 & 718 & 700 & 18 & $12 \%$ \\
\hline & & & 560 & 158 & $11 \%$ \\
\hline & & & 542 & 176 & $8 \%$ \\
\hline & & & 524 & 194 & $57 \%$ \\
\hline & & & 316 & 402 & $1 \%$ \\
\hline & & & 158 & 560 & $10 \%$ \\
\hline & & & 116 & 602 & $1 \%$ \\
\hline & 2 & $718 \rightarrow 700 \rightarrow$ & 542 & 158 & $13 \%$ \\
\hline & & & 524 & 176 & $40 \%$ \\
\hline & & & 158 & 542 & $43 \%$ \\
\hline & & & 116 & 584 & $4 \%$ \\
\hline & 2 & $718 \rightarrow 560 \rightarrow$ & 542 & 18 & $26 \%$ \\
\hline & & & 158 & 402 & $65 \%$ \\
\hline & & & 116 & 444 & $9 \%$ \\
\hline & 3 & $718 \rightarrow 718 \rightarrow 524 \rightarrow$ & 302 & 222 & $9 \%$ \\
\hline & & & 148 & 366 & $84 \%$ \\
\hline & & & 116 & 408 & $7 \%$ \\
\hline & 3 & $718 \rightarrow 560 \rightarrow 542$ & 158 & 384 & $90 \%$ \\
\hline & & & 116 & 426 & $10 \%$ \\
\hline & 3 & $718 \rightarrow 560 \rightarrow 158$ & 116 & 42 & $22 \%$ \\
\hline & & & 98 & 60 & $20 \%$ \\
\hline & & & 83 & 75 & $19 \%$ \\
\hline \multirow[t]{6}{*}{ Oleandomycin } & 1 & 688 & 544 & 144 & $42 \%$ \\
\hline & & & 302 & 386 & $1 \%$ \\
\hline & & & 158 & 530 & $54 \%$ \\
\hline & & & 116 & 572 & $3 \%$ \\
\hline & 2 & $688 \rightarrow 544$ & 158 & 386 & $96 \%$ \\
\hline & & & 116 & 428 & $4 \%$ \\
\hline \multirow[t]{7}{*}{ SP1 } & 1 & 720 & 562 & 158 & $42 \%$ \\
\hline & & & 544 & 176 & $2 \%$ \\
\hline & & & 316 & 404 & $1 \%$ \\
\hline & & & 176 & 544 & $2 \%$ \\
\hline & & & 158 & 562 & $49 \%$ \\
\hline & & & 116 & 604 & $4 \%$ \\
\hline & & & & & ntinued) \\
\hline
\end{tabular}


Table 3. Continued

\begin{tabular}{|c|c|c|c|c|c|}
\hline $\begin{array}{l}\text { Protonated } \\
\text { compounds } \\
\text { Compound }\end{array}$ & $\begin{array}{l}\text { IRMPD } \\
\text { step }\end{array}$ & $\begin{array}{l}\text { Parent }(\mathrm{m} / \mathrm{z}) \\
\text { or sequence }\end{array}$ & $\begin{array}{l}\text { Fragment } \\
\qquad(\mathrm{m} / \mathrm{z})\end{array}$ & Neutral loss & Percent \\
\hline & 2 & $720 \rightarrow 562 \rightarrow$ & 544 & 18 & $3 \%$ \\
\hline & & & 405 & 157 & $1 \%$ \\
\hline & & & 387 & 175 & $<1 \%$ \\
\hline & & & 369 & 193 & $<1 \%$ \\
\hline & & & 351 & 211 & $1 \%$ \\
\hline & & & 267 & 295 & $2 \%$ \\
\hline & & & 176 & 386 & $3 \%$ \\
\hline & & & 158 & 404 & $78 \%$ \\
\hline & & & 138 & 424 & $2 \%$ \\
\hline & & & 116 & 446 & $10 \%$ \\
\hline \multirow[t]{13}{*}{ SP2 } & 1 & 562 & 544 & 18 & $3 \%$ \\
\hline & & & 387 & 175 & $1 \%$ \\
\hline & & & 351 & 211 & $2 \%$ \\
\hline & & & 267 & 295 & $2 \%$ \\
\hline & & & 176 & 386 & $3 \%$ \\
\hline & & & 158 & 404 & $75 \%$ \\
\hline & & & 138 & 424 & $2 \%$ \\
\hline & 2 & $562 \rightarrow 544 \rightarrow$ & 176 & 368 & $10 \%$ \\
\hline & & & 158 & 386 & $58 \%$ \\
\hline & & & 138 & 406 & $11 \%$ \\
\hline & & & 116 & 428 & $21 \%$ \\
\hline & 3 & $562 \rightarrow 544 \rightarrow 176 \rightarrow$ & 158 & 18 & $89 \%$ \\
\hline & & & 116 & 60 & $11 \%$ \\
\hline \multirow[t]{17}{*}{ SP3 } & 1 & 692 & 674 & 18 & $1 \%$ \\
\hline & & & 544 & 148 & $24 \%$ \\
\hline & & & 535 & 157 & $1 \%$ \\
\hline & & & 526 & 166 & $2 \%$ \\
\hline & & & 517 & 175 & $<1 \%$ \\
\hline & & & 387 & 305 & $2 \%$ \\
\hline & & & 369 & 323 & $1 \%$ \\
\hline & & & 351 & 341 & $2 \%$ \\
\hline & & & 267 & 425 & $2 \%$ \\
\hline & & & 176 & 516 & $6 \%$ \\
\hline & & & 158 & 534 & $53 \%$ \\
\hline & & & 138 & 554 & $3 \%$ \\
\hline & & & 116 & 576 & $4 \%$ \\
\hline & 2 & $692 \rightarrow 544 \rightarrow$ & 176 & 368 & $30 \%$ \\
\hline & & & 158 & 386 & $49 \%$ \\
\hline & & & 138 & 406 & $14 \%$ \\
\hline & & & 116 & 428 & $7 \%$ \\
\hline \multirow[t]{13}{*}{ SP4 } & 1 & 653 & 635 & 18 & $1 \%$ \\
\hline & & & 517 & 136 & $13 \%$ \\
\hline & & & 505 & 148 & $1 \%$ \\
\hline & & & 487 & 166 & $4 \%$ \\
\hline & & & 369 & 284 & $13 \%$ \\
\hline & & & 351 & 302 & $29 \%$ \\
\hline & & & 333 & 320 & $9 \%$ \\
\hline & & & 266 & 387 & $5 \%$ \\
\hline & & & 241 & 412 & $7 \%$ \\
\hline & & & 227 & 426 & $9 \%$ \\
\hline & & & 120 & 533 & $9 \%$ \\
\hline & 2 & $653 \rightarrow 517 \rightarrow$ & 369 & 148 & $34 \%$ \\
\hline & & & 351 & 166 & $32 \%$ \\
\hline
\end{tabular}


Table 3. Continued

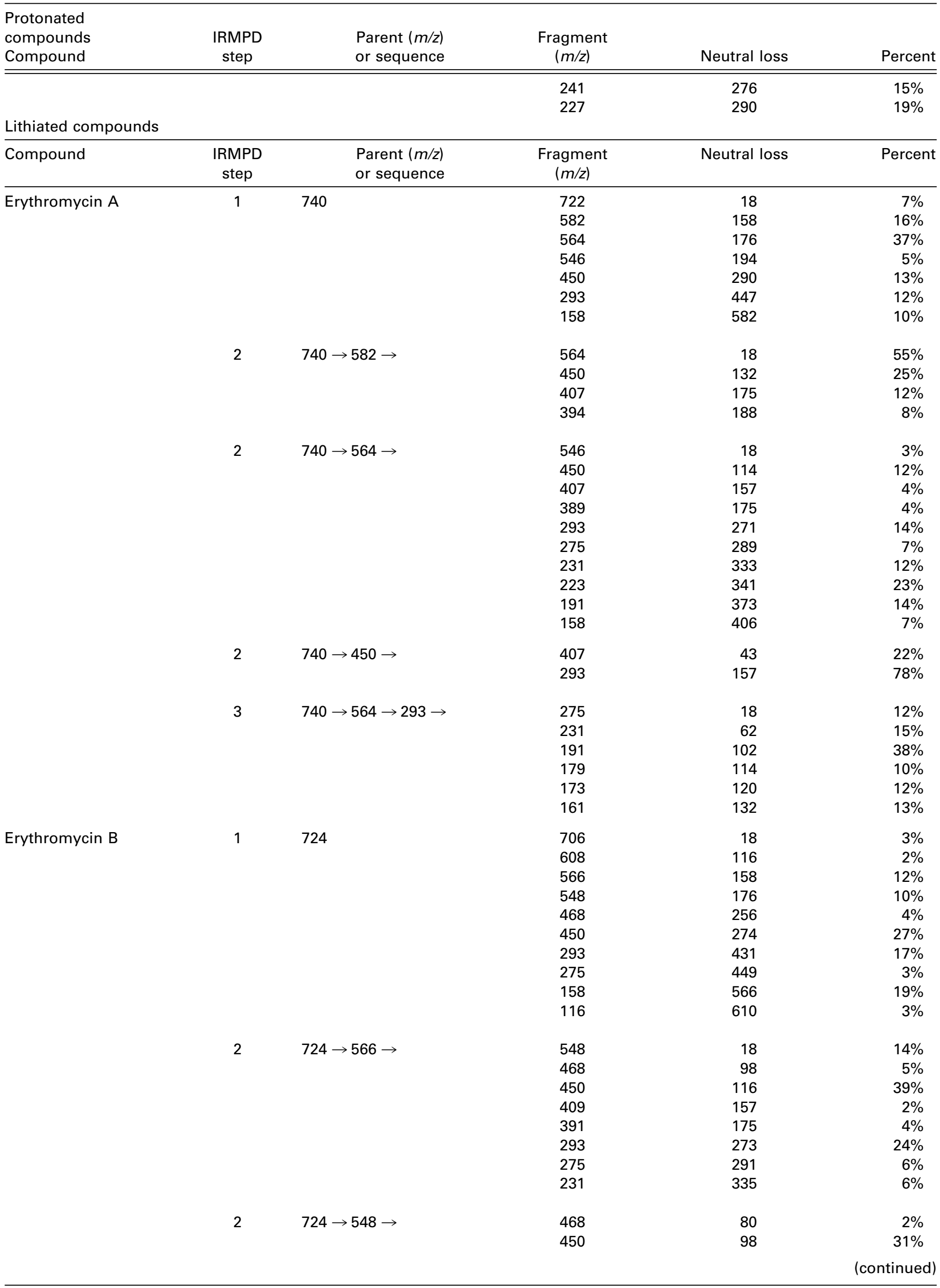


Table 3. Continued

\begin{tabular}{|c|c|c|c|c|c|}
\hline $\begin{array}{l}\text { Protonated } \\
\text { compounds } \\
\text { Compound }\end{array}$ & $\begin{array}{l}\text { IRMPD } \\
\text { step }\end{array}$ & $\begin{array}{l}\text { Parent }(\mathrm{m} / \mathrm{z}) \\
\text { or sequence }\end{array}$ & $\begin{array}{l}\text { Fragment } \\
\qquad(\mathrm{m} / \mathrm{z})\end{array}$ & Neutral loss & Percent \\
\hline & & & 432 & 116 & $3 \%$ \\
\hline & & & 409 & 139 & $2 \%$ \\
\hline & & & 391 & 157 & $4 \%$ \\
\hline & & & 293 & 255 & $26 \%$ \\
\hline & & & 275 & 273 & $7 \%$ \\
\hline & & & 231 & 317 & $8 \%$ \\
\hline & & & 188 & 360 & $13 \%$ \\
\hline & & & 158 & 408 & $6 \%$ \\
\hline & 2 & $724 \rightarrow 450 \rightarrow$ & 409 & 41 & $2 \%$ \\
\hline & & & 391 & 59 & $2 \%$ \\
\hline & & & 321 & 129 & $4 \%$ \\
\hline & & & 293 & 157 & $36 \%$ \\
\hline & & & 275 & 175 & $9 \%$ \\
\hline & & & 231 & 219 & $15 \%$ \\
\hline & & & 191 & 259 & $19 \%$ \\
\hline & & & 158 & 292 & $13 \%$ \\
\hline & 3 & $724 \rightarrow 548 \rightarrow 293 \rightarrow$ & 275 & 18 & $8 \%$ \\
\hline & & & 249 & 44 & $5 \%$ \\
\hline & & & 231 & 62 & $29 \%$ \\
\hline & & & 219 & 74 & $6 \%$ \\
\hline & & & 191 & 102 & $52 \%$ \\
\hline \multirow[t]{35}{*}{ Oleandomycin } & 1 & 694 & 664 & 30 & $1 \%$ \\
\hline & & & 610 & 84 & $1 \%$ \\
\hline & & & 550 & 144 & $27 \%$ \\
\hline & & & 537 & 157 & $3 \%$ \\
\hline & & & 532 & 162 & $1 \%$ \\
\hline & & & 466 & 228 & $5 \%$ \\
\hline & & & 393 & 301 & $1 \%$ \\
\hline & & & 375 & 319 & $1 \%$ \\
\hline & & & 309 & 385 & $1 \%$ \\
\hline & & & 158 & 536 & $55 \%$ \\
\hline & & & 116 & 578 & $4 \%$ \\
\hline & 2 & $694 \rightarrow 550 \rightarrow$ & 520 & 30 & $2 \%$ \\
\hline & & & 466 & 84 & $17 \%$ \\
\hline & & & 393 & 157 & $4 \%$ \\
\hline & & & 375 & 175 & $3 \%$ \\
\hline & & & 309 & 241 & $14 \%$ \\
\hline & & & 291 & 259 & $5 \%$ \\
\hline & & & 217 & 333 & $6 \%$ \\
\hline & & & 158 & 392 & $37 \%$ \\
\hline & & & 138 & 412 & $4 \%$ \\
\hline & & & 116 & 434 & $8 \%$ \\
\hline & 2 & $694 \rightarrow 466 \rightarrow$ & 404 & 62 & $4 \%$ \\
\hline & & & 392 & 74 & $3 \%$ \\
\hline & & & 351 & 115 & $3 \%$ \\
\hline & & & 309 & 157 & $31 \%$ \\
\hline & & & 291 & 175 & $13 \%$ \\
\hline & & & 263 & 203 & $10 \%$ \\
\hline & & & 235 & 231 & $10 \%$ \\
\hline & & & 229 & 237 & $8 \%$ \\
\hline & & & 217 & 249 & $12 \%$ \\
\hline & & & 158 & 308 & $6 \%$ \\
\hline & 3 & $694 \rightarrow 466 \rightarrow 309 \rightarrow$ & 291 & 18 & $13 \%$ \\
\hline & & & 263 & 46 & $19 \%$ \\
\hline & & & 247 & 62 & $10 \%$ \\
\hline & & & & & (continued) \\
\hline
\end{tabular}


Table 3. Continued

\begin{tabular}{|c|c|c|c|c|c|}
\hline $\begin{array}{l}\text { Protonated } \\
\text { compounds } \\
\text { Compound }\end{array}$ & $\begin{array}{l}\text { IRMPD } \\
\text { step }\end{array}$ & $\begin{array}{l}\text { Parent }(\mathrm{m} / \mathrm{z}) \\
\text { or sequence }\end{array}$ & $\begin{array}{l}\text { Fragment } \\
\qquad(\mathrm{m} / \mathrm{z})\end{array}$ & Neutral loss & Percent \\
\hline & & & 235 & 74 & $10 \%$ \\
\hline & & & 201 & 108 & $30 \%$ \\
\hline & & & 173 & 136 & $18 \%$ \\
\hline \multirow[t]{48}{*}{ SP1 } & 1 & 726 & 568 & 158 & $58 \%$ \\
\hline & & & 506 & 220 & $3 \%$ \\
\hline & & & 440 & 286 & $2 \%$ \\
\hline & & & 411 & 315 & $4 \%$ \\
\hline & & & 176 & 550 & $1 \%$ \\
\hline & & & 158 & 568 & $26 \%$ \\
\hline & & & 116 & 612 & $6 \%$ \\
\hline & 2 & $726 \rightarrow 568 \rightarrow$ & 550 & 18 & $2 \%$ \\
\hline & & & 506 & 62 & $13 \%$ \\
\hline & & & 440 & 128 & $7 \%$ \\
\hline & & & 422 & 146 & $5 \%$ \\
\hline & & & 411 & 157 & $21 \%$ \\
\hline & & & 393 & 175 & $10 \%$ \\
\hline & & & 375 & 193 & $18 \%$ \\
\hline & & & 349 & 219 & $6 \%$ \\
\hline & & & 283 & 285 & $7 \%$ \\
\hline & & & 265 & 303 & $11 \%$ \\
\hline & 3 & $726 \rightarrow 568 \rightarrow 506 \rightarrow$ & 436 & 70 & $7 \%$ \\
\hline & & & 378 & 128 & $68 \%$ \\
\hline & & & 349 & 157 & $8 \%$ \\
\hline & & & 203 & 303 & $17 \%$ \\
\hline & 3 & $726 \rightarrow 568 \rightarrow 440 \rightarrow$ & 422 & 18 & $15 \%$ \\
\hline & & & 378 & 62 & $26 \%$ \\
\hline & & & 265 & 175 & $14 \%$ \\
\hline & & & 221 & 219 & $10 \%$ \\
\hline & & & 203 & 237 & $21 \%$ \\
\hline & & & 163 & 277 & $14 \%$ \\
\hline & 3 & $726 \rightarrow 568 \rightarrow 411 \rightarrow$ & 393 & 18 & $10 \%$ \\
\hline & & & 349 & 62 & $9 \%$ \\
\hline & & & 283 & 128 & $17 \%$ \\
\hline & & & 265 & 146 & $21 \%$ \\
\hline & & & 221 & 190 & $19 \%$ \\
\hline & & & 203 & 208 & $12 \%$ \\
\hline & & & 163 & 248 & $12 \%$ \\
\hline & 3 & $726 \rightarrow 568 \rightarrow 393 \rightarrow$ & 375 & 18 & $12 \%$ \\
\hline & & & 295 & 98 & $8 \%$ \\
\hline & & & 265 & 128 & $17 \%$ \\
\hline & & & 221 & 172 & $8 \%$ \\
\hline & & & 203 & 190 & $18 \%$ \\
\hline & & & 193 & 200 & $16 \%$ \\
\hline & & & 179 & 214 & $13 \%$ \\
\hline & & & 163 & 230 & $8 \%$ \\
\hline & 3 & $726 \rightarrow 568 \rightarrow 375 \rightarrow$ & 357 & 18 & $3 \%$ \\
\hline & & & 305 & 70 & $5 \%$ \\
\hline & & & 221 & 154 & $10 \%$ \\
\hline & & & 203 & 172 & $36 \%$ \\
\hline & & & 179 & 196 & $21 \%$ \\
\hline & & & 163 & 212 & $25 \%$ \\
\hline \multirow[t]{3}{*}{ SP4 } & 1 & 659 & 641 & 18 & $1 \%$ \\
\hline & & & 523 & 136 & $16 \%$ \\
\hline & & & & & (continued) \\
\hline
\end{tabular}


Table 3. Continued

\begin{tabular}{|c|c|c|c|c|c|}
\hline $\begin{array}{l}\text { Protonated } \\
\text { compounds } \\
\text { Compound }\end{array}$ & $\begin{array}{l}\text { IRMPD } \\
\text { step }\end{array}$ & $\begin{array}{l}\text { Parent }(m / z) \\
\text { or sequence }\end{array}$ & $\begin{array}{l}\text { Fragment } \\
(\mathrm{m} / \mathrm{z})\end{array}$ & Neutral loss & Percent \\
\hline & & & 511 & 148 & $22 \%$ \\
\hline & & & 479 & 180 & $2 \%$ \\
\hline & & & 375 & 284 & $11 \%$ \\
\hline & & & 293 & 366 & $8 \%$ \\
\hline & & & 275 & 382 & $10 \%$ \\
\hline & & & 118 & 541 & $23 \%$ \\
\hline & & & 106 & 553 & $7 \%$ \\
\hline & 2 & $659 \rightarrow 523 \rightarrow$ & 375 & 148 & $4 \%$ \\
\hline & & & 293 & 230 & $16 \%$ \\
\hline & & & 231 & 292 & $20 \%$ \\
\hline & & & 189 & 334 & $16 \%$ \\
\hline & & & 128 & 395 & $15 \%$ \\
\hline & & & 118 & 405 & $15 \%$ \\
\hline & & & 106 & 417 & $14 \%$ \\
\hline & 2 & $659 \rightarrow 511 \rightarrow$ & 413 & 98 & $6 \%$ \\
\hline & & & 375 & 136 & $6 \%$ \\
\hline & & & 348 & 163 & $6 \%$ \\
\hline & & & 293 & 218 & $4 \%$ \\
\hline & & & 275 & 235 & $14 \%$ \\
\hline & & & 231 & 280 & $7 \%$ \\
\hline & & & 212 & 299 & $8 \%$ \\
\hline & & & 204 & 307 & $8 \%$ \\
\hline & & & 118 & 393 & $27 \%$ \\
\hline & & & 106 & 405 & $14 \%$ \\
\hline
\end{tabular}

\section{Conclusions}

Three main conclusions are derived from the present comparison of IRMPD and CAD for structural characterization of protonated and lithium-cationized macrolides. First, the IRMPD spectra contain key diagnostic fragment ions, especially the desosamine ion, not observed in the CAD spectra because of the trapping limitations that occur when higher mass ions are resonantly activated in the ion trap and/or lack of formation of these ions under CAD conditions. Second, multistage IRMPD proves particularly useful for confirming the genealogical relationships of dissociation, especially when low mass fragment ions that are not effectively stored under CAD conditions are formed, which ultimately gives support to the proposed fragmentation pathways and fragment ion structures. Third, the lithiumcationization process results in more extensive and more diagnostic fragmentation than that observed for the protonated macrolides. In particular, mapping of the substituents for the synthetic precursors is possible for the lithiumcationized complexes because the losses of the substituents are observed directly upon IRMPD or CAD. Moreover, characteristic cleavages of the macrolide rings are evident for the lithium-cationized complexes.

\section{Acknowledgments}

JSB acknowledges support from the National Science Foundation (CHE-9820755) and the Robert A. Welch Foundation (grant no.
F1155). The authors gratefully acknowledge Dr. Stephen F. Martin for generously supplying synthetic intermediates of erythromycin used in this study. Dr. Stephen F. Martin acknowledges support from the Robert A. Welch Foundation and the National Institutes of Health.

\section{References}

1. (a) Khosla, C. Harnessing the Biosynthetic Potential of Modular Polyketide Synthases. Chem. Rev. 1997, 97, 2577-2590. (b) Staunton, J.; Wilkinson, B. Biosynthesis of Erythromycin and Rapamycin. Chem. Rev. 1997, 97, 2611-2629.

2. Kirst, H. A. Structural Modification of Macrolide Antibiotics. In Recent Progress in the Chiral Synthesis of Antibiotics; Lukacs, G.; Ohno, M., Eds.; Springer-Verlag: Berlin, 1990; 39-63.

3. Cerny, R. L.; MacMillan, D. K.; Gross, M. L.; Mallams, A. K.; Pramanik, B. N. Fast-Atom Bombardment and Tandem Mass Spectrometry of Macrolide Antibiotics. J. Am. Soc. Mass Spectrom. 1994, 5, 151-158.

4. Gates, P. J.; Kearney, G. C.; Jones, R.; Leadlay, P. F.; Staunton, J. Structural Elucidation of Erythromycins by Electrospray Tandem Mass Spectrometry. Rapid Commun. Mass Spectrom. 1999, 13, 242-246.

5. Kearney, G. C.; Gates, P. J.; Leadlay, P. F.; Staunton, J.; Jones, R. Structural Elucidation Studies of Erythromycins by Electrospray Tandem Mass Spectrometry II. Rapid Commun. Mass Spectrom. 1999, 13, 1650-1656.

6. Volmer, D. A.; Hui, J. P. M. Study of Erythromycin A Decomposition Products in Aqueous Solution by Solid-Phase Microextraction/LiquidChromatography/Tandem MassSpectrometry. Rapid Commun. Mass Spectrom. 1998, 12, 123-129.

7. Delepine, B.; Hurtaud-Pessel, D.; Sanders, P. Multiresidue Method for Confirmation of Macrolide Antibiotics in Bovine 
Muscle by Liquid Chromatography/Mass Spectrometry. J. AOAC Int. 1996, 79, 397-404.

8. Hirsch, R.; Ternes, T. A.; Haberer, K.; Mehlich, A.; Ballwanz, F.; Kratz, K.-L. Determination of Antibiotics in Different Water Compartments via Liquid Chromatography/Electrospray Tandem Mass Spectrometry. J. Chromatog. A 1998, 815, 213223.

9. Ling, Y.-C.; Lin, L.; Chen, Y.-T. Quantitative Analysis of Antibiotics by Matrix-Assisted Laser Desorption/Ionization Time-of-Flight Mass Spectrometry. Rapid. Comm Mass Spectrom. 1998, 12, 317-327.

10. Asam, M. R.; Glish, G. L. Tandem Mass Spectrometry of Alkali Cationized Polysaccharides in a Quadrupole Ion Trap. J. Am. Soc. Mass Spectrom. 1997, 8, 987-995.

11. Hsu, F.-F.; Bohrer, A.; Turk, J. Formation of Lithiated Adducts of Glycerophosphocholine Lipids Facilitates their Identification by Electrospray Ionization Tandem Mass Spectrometry. J. Am. Soc. Mass Spectrom. 1998, 9, 516-526.

12. Olling, A.; Breimer, M. E.; Peltomaa, E.; Samuelsson, B. E.; Ghardashkhani, S. Electrospray Ionization and Collision-Induced Dissociation Time-of-Flight Mass Spectrometry of Neutral Glycosphingolipids. Rapid Commun. Mass Spectrom. 1998, $12,637-645$.

13. Madhusudanan, K. P.; Raj, K.; Bhaduri, A. P. Effect of Metal Cationization on the Low-Energy Collision-Induced Dissociation of Loganin, Epi-Loganin, and Keologanin Studied by Electrospray Ionization Tandem Mass Spectrometry. J. Mass Spectrom. 2000, 25, 901-911.

14. Stone, J. A.; Vukomanovic, D. Electrospray and Collisionally Activated Dissociation Study of the Association of Pyocyanin with Alkali Metal Cations and Doubly Charged Alkaline Earth and Zinc Cations. Int. J. Mass Spectrom. 2001, 210/211, 341-359.

15. Cui, M.; Song, F.; Liu, Z.; Liu, S. Metal Ion Adducts in the Structural Analysis of Ginsenosides by Electrospray Ionization with Multi-Stage Mass Spectrometry. Rapid Commun. Mass Spectrom. 2001, 15, 586-595.

16. Stephenson, J. L., Jr.; Booth, M. M.; Boue, S. M.; Eyler, J. R.; Yost, R. A. Analysis of Biomolecules Using Electrospray Ionization-Ion Trap Mass Spectrometry and Laser Photodissociation. In Biochemical and Biotechnological Applications of Electrospray Ionization Mass Spectrometry; Snyder, A. P., Ed.; Am. Chem. Soc.: Washington, D.C., 1996; 601.

17. Colorado, A.; Shen, J. X.; Vartanian, V. H.; Brodbelt, J. Use of Infrared Multiphoton Dissociation with SWIFT for Electrospray Ionization and Laser Desorption Applications in a Quadrupole Ion Trap Mass Spectrometer. Anal. Chem. 1996, 68, 4033-4043.

18. Little, D. P.; Speir, J. P.; Senko, M. W.; O'Connor, P. B.; McLafferty, F. W. Infrared Multiphoton Dissociation of Large Multiply Charged Ions for Biomolecule Sequencing. Anal. Chem. 1994, 66, 2809-2815.

19. Goolsby, B. J.; Brodbelt, J. S. Characterization of $\beta$-lactams by Photodissociation and Collision Activated Dissociation in a Quadrupole Ion Trap. J. Mass Spectrom. 1998, 33, 705-712.
20. Vartanian, V. H.; Goolsby, B.; Brodbelt, J. S. Identification of Tetracycline Antibiotics by Electrospray Ionization in a Quadrupole Ion Trap. J. Am. Soc. Mass Spectrom. 1998, 9, 1089-1098.

21. Shi, S. D.-H.; Hendrickson, C. L.; Marshall, A. G.; Siegel, M. M.; Kong, F.; Carter, G. T. Structural Validation of Saccharomyces by High Resolution and High Mass Accuracy Fourier Transform-Ion Cyclotron Resonance Mass Spectrometry and Infrared Multiphoton Dissociation Tandem Mass Spectrometry. J. Am. Soc. Mass Spectrom. 1999, 10, 1285-1290.

22. Little, D. P.; Aaserud, D. J.; Valaskovic, G. A.; McLafferty, F. W. Sequence Information from 42-108-mer DNAs (Complete for a 50-mer) by Tandem Mass Spectrometry. J. Am. Chem. Soc. 1996, 118, 9352-9359.

23. Li, W.; Hendrickson, C. L.; Emmett, M. R.; Marshall, A. G. Identification of Intact Proteins in Mixtures by Alternated Capillary Liquid Chromatoraphy Electrospray Ionization and LC ESI Infrared Multiphoton Dissociation Fourier Transform Ion Cyclotron Resonance Mass Spectrometry. Anal. Chem. 1999, 71, 4397-4402.

24. Hofstadler, S. A.; Sannes-Lowery, K. A.; Griffey, R. H. Infrared Multiphoton Dissociation in an External Ion Reservoir. Anal. Chem. 1999, 71, 2067-2070.

25. Goolsby, B. J.; Brodbelt, J. S. Analysis of Protonated and Alkali Metal Cationized Aminoglycoside Antibiotics by Collisional Activated Dissociation and Photodissociation in a Quadrupole Ion Trap. J. Mass Spectrom. 2000, 35, 1011-1024.

26. Goolsby, B. J.; Brodbelt, J. S. Tandem Infrared Multiphoton Dissociation and Collisionally Activated Dissociation Techniques in a Quadrupole Ion Trap. Anal. Chem. 2001, 73, 1270-1276.

27. Hakansson, K.; Cooper, H. J.; Emmett, M. R.; Costello, C. E.; Marshall, A. G.; Nilsson, C. L. Electron Capture Dissociation and Infrared Multiphoton Dissociation MS/MS of an NGlycosylated Tryptic Peptide to Yield Complementary Sequence Information. Anal. Chem. 2001, 73, 4530-4536.

28. Flora, J. W.; Muddiman, D. C. Selective, Sensitive, and Rapid Phosphopeptide Identification in Enzymatic Digests Using ESI-FTICR-MS with Infrared Multiphoton Dissociation. Anal. Chem. 2001, 73, 3305-3311.

29. Payne, A. H.; Glish, G. L. Thermally Assisted Infrared Multiphoton Photodissociation in a Quadrupole Ion Trap. Anal. Chem. 2001, 73, 3542-3548.

30. Van Berkel, G. J.; Glish, G. L.; McLuckey, S. A. Electrospray Ionization Combined with Ion Trap Mass Spectrometry. Anal. Chem. 1990, 62, 1284-1295.

31. Wiley, P. F.; Sigal, M. V.; Weaver, O.; Monahan, R.; Gerzon, K. Erythromycin. XI. Structure of Erythromycin B. J. Am. Chem. Soc. 1957, 79, 6070-6074.

32. Martin, S. F.unpublished.

33. Martin, S. F.; Hida, T.; Kym, P. R.; Loft, M.; Hodgson, A. The Asymmetric Synthesis of Erythromycin B. J. Am. Chem. Soc. 1997, 119, 3193-3194. 